\title{
Polymers with lonic Liquid Fragments as Potential Conducting Materials for Advanced Applications
}

\author{
Santiago V. Luis ${ }^{1}$, Eduardo García-Verdugo스. M. Isabel Burguete', \\ Andreu Andrio'2, Sergio Mollá ${ }^{3}$ and Vicente Compan ${ }^{3}$ \\ ${ }^{1}$ Departamento de Química Orgánica, Universitat Jaume I., Castellón, \\ ${ }^{2}$ Departamento de Física, Universitat Jaume I., Castellón, \\ ${ }^{3}$ Departamento de Termodinámica Aplicada, Universidad Politécnica de Valencia, Valencia,
}

Spain

\section{Introduction}

During the last decades, the use of ionic liquids (ILs) has become one of the most useful techniques for the development of green chemistry tools. ${ }^{1}$ The potential use of liquid salts based on delocalized organic cations (ammonium or phosphonium) as designer green solvents represents one of the most significant contributions to modern chemistry. Thus, the high modularity of the structures of the ILs based on the proper selection of the cation and anion moieties has allowed the development of an almost infinite number of compounds well suited for each specific application. Nevertheless, in recent years, the application of ILs also needs to confront some important challenges in order to be able to develop the expected practical applications. ${ }^{2}$ Thus, some important drawbacks are limiting the general application of ILs in scientific and technological applications. First of all, the cost of ILs is clearly much higher than that for traditional solvents. Additionally, the benefits of the use of ILs as media for different chemical reactions and other applications is counterbalanced by the need of using traditional "non-green" solvents for the extraction of the desired products from the IL phase. Finally, recent studies have shown that, although ILs have been considered traditionally as environmentally friendly solvents because of the lack of any appreciable vapor pressure, some of the most usual ILs present some environmental concerns in particular in terms of their contact with aqueous media. ${ }^{3}$ Many of those drawbacks can be drastically reduced by the use of supported ILs. The immobilization of ILs onto a solid support provides a simple way for reducing the amount of IL required for a given application, reducing accordingly the associated cost; facilitates their handling and manipulation decreasing the need of using traditional solvents in the corresponding process, and finally, greatly reduces the potential leaching to the environment of the ILs. ${ }^{4}$

In order to accomplish this target two main approaches have been studied:

1. Non-covalent support of IL phases on the surface of inorganic or organic supports (SILPs).

2. Covalent attachment of IL-like phases on the surface of inorganic or organic supports (SILLPs). 
It seems clear to understand that the development of SILLPs presents some methodological advantages. In particular, it should be expected that the use of IL phases physically entrapped onto the surface of a given support would maintain the essential properties of the corresponding bulk IL, as no change in the structure is carried out through this process. On the contrary, the potential leaching of the supported IL phases in the presence of a solvent being able to partially solvate the IL structure represents the main limitation of this approach. The almost opposite reasoning is valid for the second approach. In this case, when the IL-like fragment is covalently attached to the support, the problem of leaching is totally eliminated. On the contrary, the transfer of the proper essential properties of the ILs to the solid phase needs to be guaranteed, and this is not a simple matter. However, it is reasonable to assume that if this goal of transferring IL properties to the surface of the solid is achieved, the resulting materials would present the advantages associated to ILs but would overcome the abovementioned drawbacks currently limiting many technological applications of bulk Ionic Liquids.

In recent years, most emphasis has been given to the application of ILs as selective and very specialized media for carrying out chemical transformations, including catalytic ${ }^{5}$ and biocatalytic $^{6}$ applications or the extraction, ${ }^{7}$ manipulation and transformation of natural products and biopolymers. ${ }^{8}$ Nevertheless, it is important to bear in mind that the first applications of ILs were described in the field of the development of new electrolytes for advanced applications such as those involving new sensors, fuel cells, conducting materials or other applications in the general area of renewable energy sources. ${ }^{9}$ In this regard, it is not surprising that the development of solid electrolytes based on the structures of ILs has received a great deal of attention, taking into account some of the advantages considered for SILPs and SILLPs. 10

Thus, polymeric ILs represents an important field in the area of new advanced materials for energy applications. ${ }^{11}$ Nevertheless, most applications in this field have been associated to the development of soluble polymers containing structural moieties related to ILs: imidazolium, phosphonium or ammonium groups. ${ }^{12}$ The use of those polymers as conducting material can be easily rationalized in terms of the mobility of the polymeric chains carrying out the ionic species and giving place to the conduction phenomena. ${ }^{13}$ Much less attention has been paid, however, to the study of insoluble polymers containing such structures. This is an interesting field because those materials can provide in full the advantages we have considered for supported ILs and because their study as conducting materials can provide some important insights on the conduction mechanisms in ILs. Here we will examine and discuss some essential properties of polymer-supported Ionic Liquidlike Phases (SILLPs), using crosslinked insoluble matrices as supports, and their behavior as conducting polymers. The importance of those materials has been highlighted by their application as "solid solvents" for the immobilization of different catalytic species that reveal that the corresponding polymers can advantageously substitute for the related bulk ILs for this purpose. ${ }^{14}$

\section{Approaches for the preparation of polymeric-ILs}

In general the preparation of SILPs in which the IL fragment is non-covalently attached onto the surface of a solid support, usually an inorganic support such as $\mathrm{SiO}_{2}$, is carried out by the adsorption of a thin layer of a bulk IL onto the surface of the corresponding support (see Figure 1a). In some cases, however, it has been demonstrated that the previous modification 
of the structure of the support, in particular through the introduction of IL-like fragments provides an efficient way to improve the immobilization process and reduces the risk of leaching (see Figure 1b).

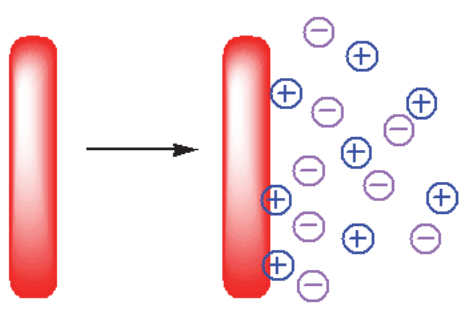

a: SILPs

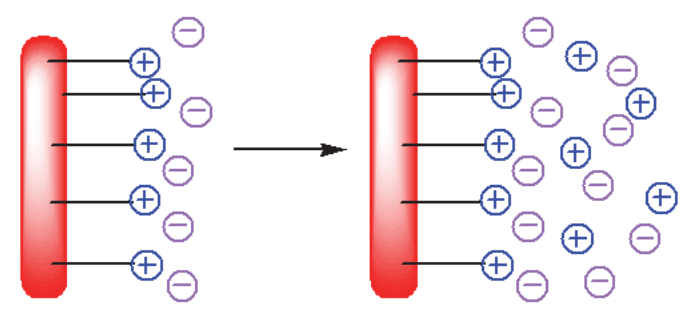

b: SILLPs

Fig. 1. General structures for SILPs (a) and SILLPs (b).

In the case of the preparation of SILLPs, it is considered that the modification of the structure of a support with the introduction of IL-like fragments such as imidazolium, phosphonium, ammonium or others will be able to transfer to this surface the properties of the related bulk IL. Two main approaches can be considered for this purpose in the case of organic polymers. The first one is the polymerization of the corresponding monomers containing IL fragments. This is exemplified in Figure 2 for the case of polystyrenedivinylbenzene backbones with imidazolium subunits. In the case of the use of monomeric mixtures just containing styrene (1) and functionalized styrene monomers (3) the resulting materials will be linear soluble polymers. When variable amounts of a crosslinking agent are added (i. e. divinylbenzene, DVB 2) the corresponding insoluble polymers can be obtained. When those polymers are prepared in the form of monoliths through a bulk polymerization process, the resulting materials can be easily obtained with different morphologies and shapes, according to the desired application. A more simple and versatile approach, however, for the preparation of those materials is the use of common polymeric precursors having the appropriate morphological and chemical properties. This is exemplified in Figure 3 , in which chloromethylstyrene is used for the introduction of the precursor functionalities in the crosslinked polymeric backbone. The transformation of chloromethyl groups into the corresponding IL-like fragments (i.e. imidazolium groups) is very simple and can be carried out very efficiently. A quantitative transformation of the functional groups can be obtained after a few hours of heating of the corresponding polymer with the desired imidazole used as the reagent and the solvent. The progress of the process can be easily monitored through different methods that have been developed for analysing the transformation of chloromethyl groups. The advantage of this approach is that the polymerization of mixtures of styrene, divinylbenzene and chloromethylstryrene, in the presence of porogenic agents, is a well-known process and accordingly can be controlled, in terms of yields, conversions, morphology and so on, using standarised parameters. On the contrary, the introduction in the polymerization mixture of monomers such as 3 with very different structural and electronic properties can provide very different outcomes, according to the different polymerization rates and to the different monomers/oligomers/porogens solubility equilibria occurring in the global process. Finally, it must be noted that a simple metathesis 
procedure, as reported for bulk ILs, allows for the exchange of the initial chloride counteranion for any other anion of interest in the area of ILs. All those transformations can be easily monitored through the use of FT-IR spectroscopy and, very particularly in the case of the modification of the anions, with the use of FT-Raman spectroscopy. ${ }^{14}$

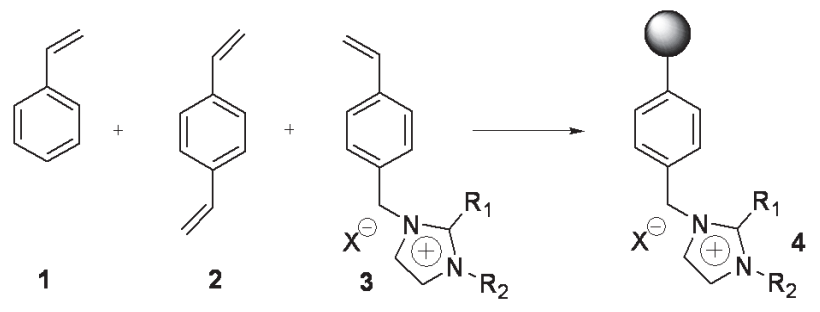

Fig. 2. Synthesis of SILLPs by polymerization of vinyl imidazolium monomers.

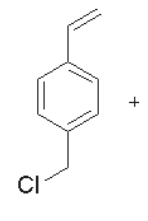

1

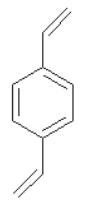

2

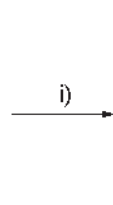

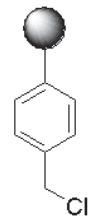

5

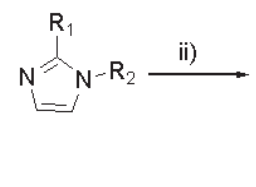

6
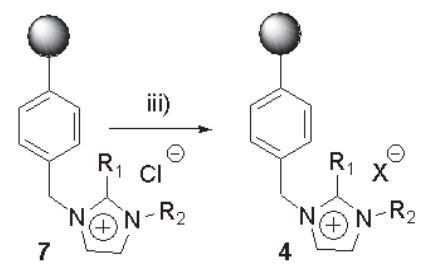

Fig. 3. Synthesis of SILLPs by modification of preformed polymers.

\section{Properties of polymeric ionic liquids (SILLPs)}

The potential application of the polymeric SILLPs prepared by any of the methodologies considered above is associated to the presence of some important properties according to the desired application. Some of them are associated to the morphology and the chemical properties of the polymeric backbone (thermal stability, porosity, surface...). In our case, however, the priority is to understand if the presence of the ionic liquid-like fragments on the surface of the polymer is able to transfer to this material the essential properties associated with the bulk ILs. In this regard, we have approached this subject through the analysis of a variety of properties characteristic of ILs on the corresponding polymeric SILLPs (4). As we will see below, we have been able to demonstrate that many of those properties are efficiently transferred to the polymer. ${ }^{15}$ Moreover, we have checked that modifications on the structural parameters of the IL-like fragments provide a method to modulate the properties of the resulting material. This is an essential factor as much as some of the most important applications of ILs rely on their potential as "designer solvents" being able to provide the desired properties, almost in an unlimited way, through the proper modular modification of their structural parameters.

\section{Thermal stability}

For many applications, the thermal stability of ILs and SILLPs is a critical parameter. ${ }^{16}$ In this regard we have carried out thermogravimetric (TGA) and differential scanning 
calorimetry (DSC) studies for the different SILLPs synthesised. Very interestingly, TGA data clearly show that the presence of imidazolium subunits provide an additional stabilisation of the SILLP when compared with the starting chloromethylated resin, which is rather surprising taking into account the presence of benzyl imidazolium subunits. This is, however, in good agreement with the studies on bulk ILs revealing the high thermal stability of those species. Some results from TGA analyses of SILLPs 4 are gathered on Figure 4 and demonstrate that those polymers follow the same trends observed for bulk ILs. Thus, the nature of the anion is the main parameter determining the thermal stability. This is higher for the less nucleophilic anions and lower for the most nucleophilic ones. The observed effects slightly increase with the loading of functional groups in the polymer. Thus the two extreme cases, in terms of the anion used, correspond, as we will see in all cases, to the chloride and the $\mathrm{NTf}_{2}{ }^{-}$anion. Although it is not represented in Figure 4, it is interesting to note that changes in the aliphatic chain of the imidazolium ring (i.e. changing from $R_{2}=$ $\mathrm{CH}_{3}$ to $\mathrm{R}_{2}=\mathrm{C}_{4} \mathrm{H}_{9}$ ) have a much less pronounced effect on the thermal stability. The use of DSC techniques provides some additional information (Figure 5). DSC thermograms show the presence of small transitions on the SILLPs at temperatures well below the decomposition temperature. Those transitions can be associated to the movement of noncrosslinked polymeric chains. As can be seen in Figure 5, those transitions are very much affected by the nature of the counter anion. Thus, for instance, the exchange of $\mathrm{Cl}^{-}$by $\mathrm{NTf}_{2}{ }^{-}$ involves a reduction in the corresponding Tg from about $110^{\circ} \mathrm{C}\left(4, \mathrm{R}_{2}=\mathrm{C}_{4} \mathrm{H}_{9}, \mathrm{R}_{1}=\mathrm{CH}_{3}, \mathrm{X}=\right.$ $\mathrm{Cl})$ to $50^{\circ} \mathrm{C}\left(4, \mathrm{R}_{2}=\mathrm{C}_{4} \mathrm{H}_{9}, \mathrm{R}_{1}=\mathrm{CH}_{3}, \mathrm{X}=\mathrm{NTf}_{2}\right)$. This suggests that the presence of the more coordinating anion provides a strong ordering of the structure through polymeric anioncation interactions. It can be also seen that the presence of an acidic $\mathrm{H}$ atom at being able to participate in hydrogen bonding is accompanied by a small increase in this $\mathrm{Tg}$. This is augmented in the case of the presence of the $\mathrm{Cl}^{-}$anion. This indicates that intermolecular hydrogen bonding can play a role in determining intermolecular anion-cation interactions.

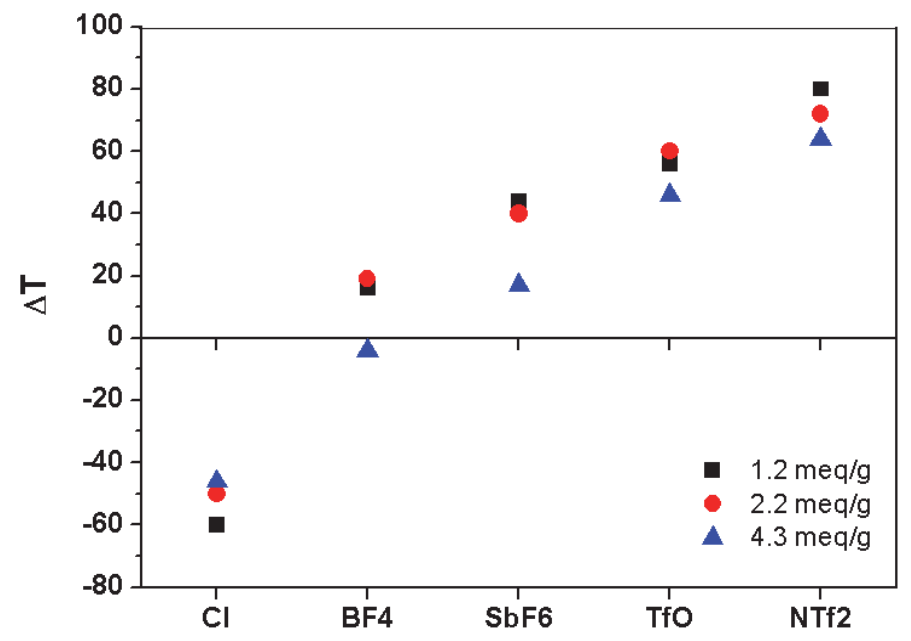

Fig. 4. Effect of loading and nature of the anion on the thermal stability of SILLPs as measured by TGA. $\Delta \mathrm{T}$ is defined as the difference in thermal stability between the starting Merrifield's resin (5) and the polymer with the corresponding imidazolium subunits (4). 


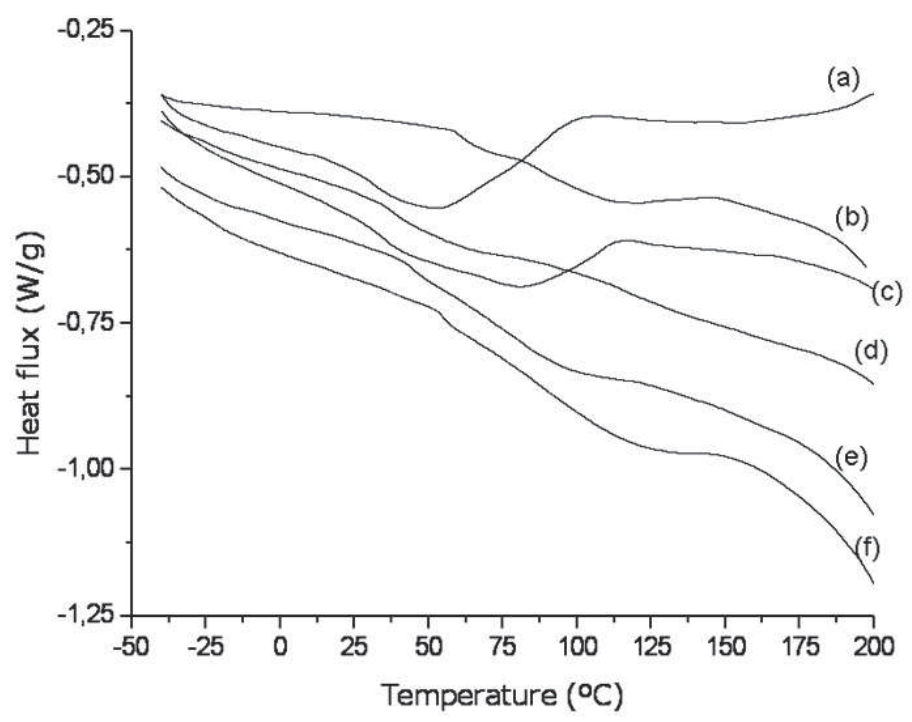

Fig. 5. DSC curves for different SILLPs 4: (a) $\mathrm{KN10}\left(\mathrm{R}_{1}=\mathrm{CH}_{3}, \mathrm{R}_{2}=\mathrm{CH}_{3}, \mathrm{X}=\mathrm{NTf}_{2}\right)$, (b) KN5 $\left(\mathrm{R}_{1}=\mathrm{H}, \mathrm{R}_{2}=\mathrm{CH}_{3}, \mathrm{X}=\mathrm{Cl}\right)$, (c) KN9 $\left(\mathrm{R}_{1}=\mathrm{H}, \mathrm{R}_{2}=\mathrm{C}_{4} \mathrm{H}_{9}, \mathrm{X}=\mathrm{NTf}_{2}\right)$, (d) KN6 $\left(\mathrm{R}_{1}=\mathrm{H}, \mathrm{R}_{2}=\mathrm{CH}_{3}\right.$, $\left.\mathrm{X}=\mathrm{NTf}_{2}\right)$, (e) KN7 $\left(\mathrm{R}_{1}=\mathrm{H}, \mathrm{R}_{2}=\mathrm{C}_{4} \mathrm{H}_{9}, \mathrm{X}=\mathrm{Cl}\right)$ and (f) $\mathrm{KN} 8\left(\mathrm{R}_{1}=\mathrm{CH}_{3}, \mathrm{R}_{2}=\mathrm{CH}_{3}, \mathrm{X}=\mathrm{Cl}\right)$.

Second run.

\section{Assessment of polarity through solvatochromic probes}

An important property of ILs is that significant changes in their polarity can be achieved through changes in their structure, either by modification of the imidazolium substituents or by modification of the counteranion. ${ }^{17}$ In this regard polarity assessment through the use of solvatochromic probes is one of the most simple and accessible techniques for a rapid and semiquantitative analysis. In our case, we have selected two well known solvatochromic probes - pyrene ${ }^{18}$ and Reichardt's probe ${ }^{19}$ to analyze the properties of the SILLPs. Figure 6 includes some of the data obtained with the use of Reichardt's probe. As can be observed, values obtained for ET(N) in SILLPs are in good agreement with those reported for related bulk ILs (butyl imidazolium salts: BMIM). ${ }^{20}$ In this case it is easy to observe that the introduction of larger aliphatic chains is accompanied by a decrease in polarity as described by the ET(N) parameter, although a clear pattern associated to the nature of the anion is not detected, according to a similar observation in solution. The effect of the anion is more visible, however, when pyrene is used as the fluorescent probe, using the I3/I1 ratio as a measure of polarity (see Figure 7). ${ }^{21}$ In this case the more coordinating anion $\left(\mathrm{Cl}^{-}\right)$is associated to a higher value of polarity (higher value of I3/I1), whereas the presence of the less coordinating $\mathrm{NTf}_{2}{ }^{-}$anion gives place to a lower value of I3/I1. Here, however, a clear pattern for the substitution of methyl by butyl in the cation is not detected. In any case the general values obtained are again in good agreement with the values obtained in solution for related solvents and materials and bulk ILs. ${ }^{22}$ As clearly seen from the above data, as much as the former solvathochromic parameters are dependent on adsorption phenomena on a heterogeneous surface, the quantitative data obtained must be handled with caution 
and a more accurate method for polarity determination (see below) is required for properly determining this essential property.

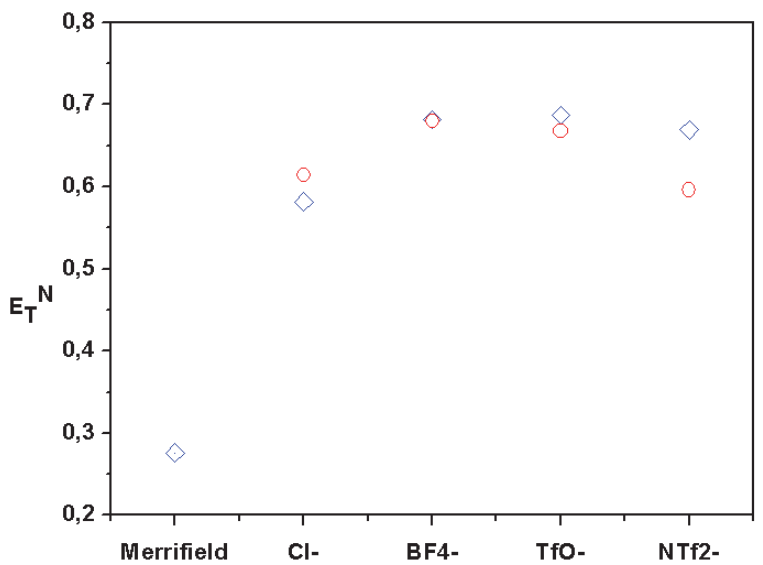

Fig. 6. Effect of the nature of the anion of the ET(N) solvathochromic parameter using the Reichart's probe. Comparison with related bulk ILs. Red circles indicate BMIMX bulk ILs; blue diamonds refer to the corresponding SILLPs.

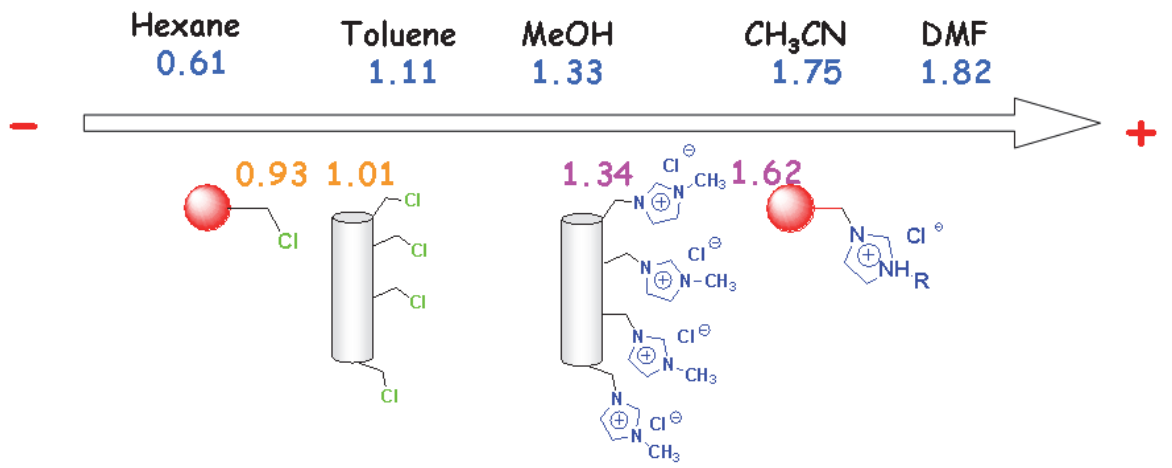

Fig. 7. Polarity determination of SILLPs using the I3/I1 ratio pyrene as the fluorescent probe.

\section{Compatibility with polar solvents; swelling analysis}

Gel-type polymers containing low levels of crosslinkers and prepared in the absence of porogenic agents are characterized by the absence of any permanent porosity in the dry state. Thus, the use of those polymers for applications requiring the accessibility of the functional sites on the polymeric backbone is always associated to the presence of a good solvent, compatible with the matrix, being able to expand the polymeric chains. ${ }^{23}$ In general, PS-DVB polymers can be considered as hydrophobic materials, not being compatible with 
the use of polar solvents such as water or methanol. It can be expected that the introduction of imidazolium or other IL-like subunits will provide an important change in the polarity of the matrix, favouring the swelling of the polymer by polar solvents. In this regard, the swelling of a polymer with a polar solvent such as water (as determined through the change of the diameter from the dry to the swollen state) can be considered an indirect measurement of polarity. Although the corresponding values cannot be used for a quantitative assessment of polarity, they represent a very interesting parameter for practical applications as with the use of water (and other polar solvents). Figure 8 shows some data obtained for SILLPs prepared from a gel-type Merrifield resin with a high loading of functional groups $(4.3 \mathrm{mmol} \mathrm{Cl} / \mathrm{g})$. This figure allows observing the expected trends associated to the changes in the structure of the IL-like fragment. Thus, when analysing the nature of the anion, it can be clearly seen that the presence of the $\mathrm{Cl}^{-}$anion results in more polar resins. On the other hand, the substitution of the methyl substituent $\left(\mathrm{R}=\mathrm{CH}_{3}\right)$ by a more lipophilic one $\left(\mathrm{R}=\mathrm{C}_{4} \mathrm{H}_{9}\right)$ produces an appreciable decrease of the polarity.

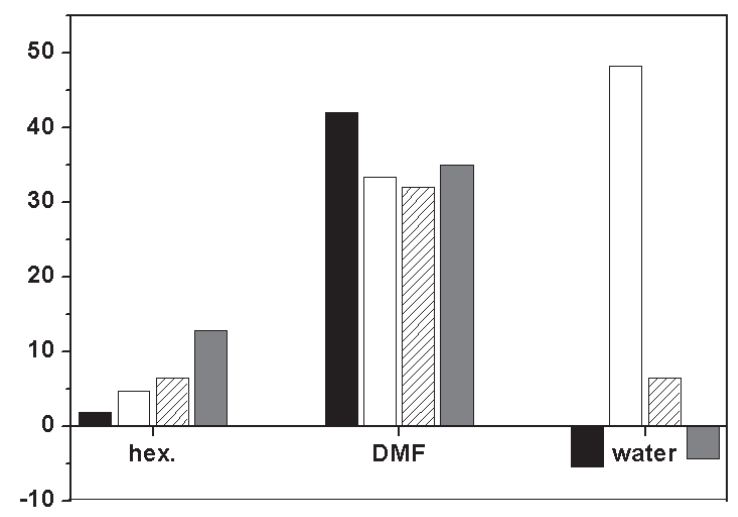

Fig. 8. Swelling effects for different solvents in SILLPs differing on the nature of the anion. Black bars: starting Merrifield's resin; white bars: SILLP with $\mathrm{Cl}^{-}$anion; stripped bars: $\mathrm{BF}_{4}^{-}$ anion; grey bars: $\mathrm{NTf}_{2}-$ anion.

\section{Dielectric relaxation spectroscopy}

The different crosslinked polystyrene resins containing ionic liquid fragments covalently attached (Supported Ionic Liquid-Like Phases: SILLPs) indicated above has been studied by means of dielectric impedance spectroscopy to obtain the conductivity. Impedance experiments were carried out on SILLPs samples at several temperatures lying in the range $298 \mathrm{~K}\left(25^{\circ} \mathrm{C}\right)$ to $398 \mathrm{~K}\left(125^{\circ} \mathrm{C}\right)$ and frequency window $10^{-2}<f<10^{6} \mathrm{~Hz}$. The measurements were performed with $100 \mathrm{mV}$ amplitude, using a Novocontrol broadband dielectric spectrometer (Hundsangen, Germany) integrated by a SR 830 lock-in amplifier with an Alpha dielectric interface. The SILLP sample of interest was placed between two gold electrodes coupled to the impedance spectrometer. The area of the electrodes was $20 \mathrm{~mm}^{2}$. The temperature was controlled by a nitrogen jet (QUATRO from Novocontrol) with a temperature error of $0.1 \mathrm{~K}$ during every single sweep in frequency. 


\section{Analysis from Bode and Nyquist diagrams}

Under an alternating electric field, the response of dipoles associated with molecules or segments of chain molecules to the field as well as the ions movements depend on the physical state (glassy, liquid) of the system. The impedance response is usually measured with blocking electrode/polar system/blocking electrode configuration. Polarization processes arising from dipole motions in polar systems can empirically be represented by an equivalent circuit consisting of a resistance, $R_{p}$, accounting for the polarization of the system in parallel with a capacitor of capacity $C$ that describes the interfacial double layer capacitance system-blocking electrode. ${ }^{24}$ The complex impedance of the circuit is given by

$$
Z^{*}(\omega)=\frac{R_{p}}{1+j \omega R_{p} C}=\frac{R_{p}}{1+j \omega \tau}
$$

where $R_{p} C$, which has the dimensions of time, is replaced for $\tau$, called relaxation time. Eq. 1 suggests that a plot of $Z^{\prime \prime}(\omega)$ against $Z^{\prime}(\omega)$ should be a semicircle centered at $Z^{\prime}=R_{p} / 2$ that intersects the abscissa axis at the origin $(\omega \rightarrow \infty)$ and $Z^{\prime}=R_{p}(\omega \rightarrow 0)$. Relaxations defined by a single relaxation time are called Debye type processes. However, polarization processes in condensed matter are not defined by a single relaxation time, but by a distribution of relaxation times, in such a way that the complex impedance should be written as

$$
Z *(\omega)=\sum_{i} w_{i} \frac{R_{p ; i}}{1+j \omega \tau_{i}}
$$

where $w_{i}$ is the fraction of relaxation mechanism $i$ with polarization resistance $R_{p i}$ and relaxation time $\tau_{i}$. As in the case of Debye systems, the $Z^{\prime \prime}$ vs $Z^{\prime}$ plots are curves that intersect the abscissa axis at the origin $(\omega \rightarrow \infty)$ and $Z^{\prime}=\sum_{i=1}^{n} R_{p i}(\omega \rightarrow 0)$. The impedance behavior of these complex systems can be represented by an equivalent circuit consisting of a polarization resistance in parallel with a constant phase element, CPE, provided of an admittance $Y^{*}=Y_{0}(j \omega \tau)^{n}$, with $n$ lying in the range $0<n \leq 1$ and $Y_{0}$ given in $\Omega^{-1}$ units. ${ }^{25}$ The impedance of the circuit is given by

$$
Z^{*}(\omega)=\frac{R_{p}}{1+Y_{1}(j \omega \tau)^{n}}
$$

Where, $Y_{1}=Y_{0} R_{p}$. Notice that for $n=Y_{1}=1$, eq. 3 corresponds to the complex impedance of a Debye system.

For systems that combine polarization processes with a resistance independent on frequency or ohmic resistance, $R_{o}$, the electrical equivalent circuit is a parallel R-CPE circuit in series with an assembly of $\mathrm{N}$ circuits in series. Each circuit is made up of a resistance $R_{i}$ that represent a polarization resistance in parallel with a constant phase element. The complex impedance of the circuit can be written as

$$
Z^{*}(\omega)=R_{0}+\sum_{i=1}^{N} \frac{R_{i}}{1+R_{i} Y_{0 i}\left(j \omega \tau_{i}\right)^{n_{i}}}
$$


The real and imaginary parts of $Z^{*}$ are

$$
\begin{aligned}
& Z^{\prime}(\omega)=R_{0}+\sum_{i=1}^{N} \frac{R_{i}+Y_{0 i} R_{i}^{2}\left(\omega \tau_{i}\right)^{n_{i}} \cos \frac{n_{i} \pi}{2}}{1+Y_{0 i} R_{i}^{2}\left(\omega \tau_{i}\right)^{2 n_{i}}+2 Y_{0 i} R_{i}\left(\omega \tau_{i}\right)^{n_{i}} \cos \frac{n_{i} \pi}{2}} \\
& Z^{\prime \prime}(\omega)=-\sum_{i=1}^{N} \frac{Y_{0 i} R_{i}^{2}\left(\omega \tau_{i}\right)^{n_{i}} \sin \frac{n_{i} \pi}{2}}{1+Y_{0 i} R_{i}^{2}\left(\omega \tau_{i}\right)^{2 n_{i}}+2 Y_{0 i} R_{i}\left(\omega \tau_{i}\right)^{n_{i}} \cos \frac{n_{i} \pi}{2}}
\end{aligned}
$$

It is worth noting that the resistance $R_{0}$ is obtained from the Bode diagrams ${ }^{26}$ in which the complex impedance modulus, $\left|Z^{*}(\omega)\right|=\left[Z^{\prime 2}(\omega)+Z^{\prime \prime 2}(\omega)\right]^{1 / 2}$, is plotted against frequency. For R-CPE parallel circuits, $\lim _{\omega \rightarrow 0}|Z(\omega)|=R_{p}$ and $\lim _{\omega \rightarrow \infty}|Z(\omega)|=0$, whereas for circuits made up of a parallel R-CPE circuit in series with an ohmic resistor, $\lim _{\omega \rightarrow 0}|Z(\omega)|=R_{p}+R_{o}$ and $\lim _{\omega \rightarrow \infty}|Z(\omega)|=R_{o}$. In the latter case, the curve describing the dependence of the modulus of the impedance on frequency decreases from $R_{p}+R_{o}$, at low frequencies $(\omega \rightarrow 0)$, where a plateau is reached until high frequencies $(\omega \rightarrow \infty)$ at which $/ Z^{*}\left(\omega /\right.$ tends to $R_{0}$. Moreover, the phase angle of the impedance $\phi=\tan ^{-1}\left[-Z^{\prime}(\omega) / Z^{\prime \prime}(\omega)\right]$ increases with frequency decrease from $-90^{\circ}$ at $\omega \rightarrow \infty$ to $0^{\circ}$ at $\omega \rightarrow 0$. Then $R_{o}$ is taken as the modulus of the impedance at the plateau coexisting with $\phi=0$. Bode diagrams in terms of the complex modulus of the conductivity obtained by means of $\left|\sigma^{*}(\omega)\right|=\frac{1}{\left|Z^{*}(\omega)\right|}$ are represented for KN8 and $\mathrm{KN} 10$ in the temperature range $298 \mathrm{~K}$ to $398 \mathrm{~K}$ are shown in Figures 9 and 10, respectively.

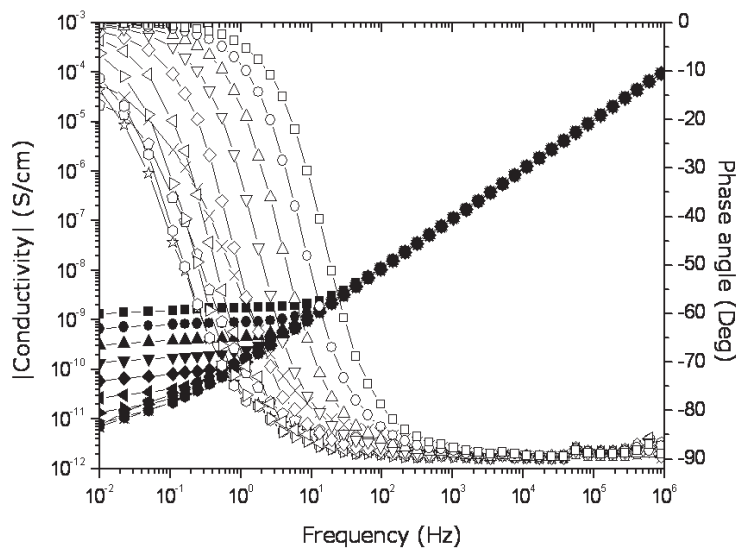

Fig. 9. Bode diagrams for $\mathrm{KN} 8\left(4, \mathrm{R}_{1}=\mathrm{CH}_{3}, \mathrm{R}_{2}=\mathrm{CH}_{3}, \mathrm{X}=\mathrm{Cl}\right)$ showing the logarithm of the conductivity and the phase angle at several temperatures: (square) 398K, (circle) 388K, (up triangle) 378K, (down triangle) 368K, (diamond) 358K, (left triangle) 348K, (right triangle) $338 \mathrm{~K}$, (hexagon) 328K, (star) 318K, (pentagon) 308K and (plus) 298K. Solid symbols for impedance and open symbols for phase angle. 


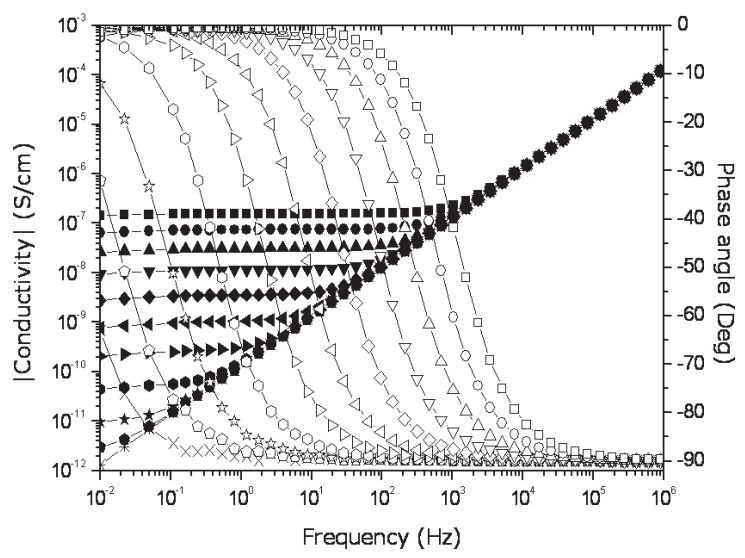

Fig. 10. Bode diagrams for $\mathrm{KN10}\left(4, \mathrm{R}_{1}=\mathrm{CH}_{3}, \mathrm{R}_{2}=\mathrm{CH}_{3}, \mathrm{X}=\mathrm{NTf}_{2}\right)$ showing the logarithm of the conductivity and the phase angle at several temperatures: (square) 398K, (circle) 388K, (up triangle) 378K, (down triangle) 368K, (diamond) 358K, (left triangle) 348K, (right triangle) 338K, (hexagon) 328K, (star) 318K, (pentagon) 308K and (plus) 298K. Solid symbols for impedance and open symbols for phase angle.

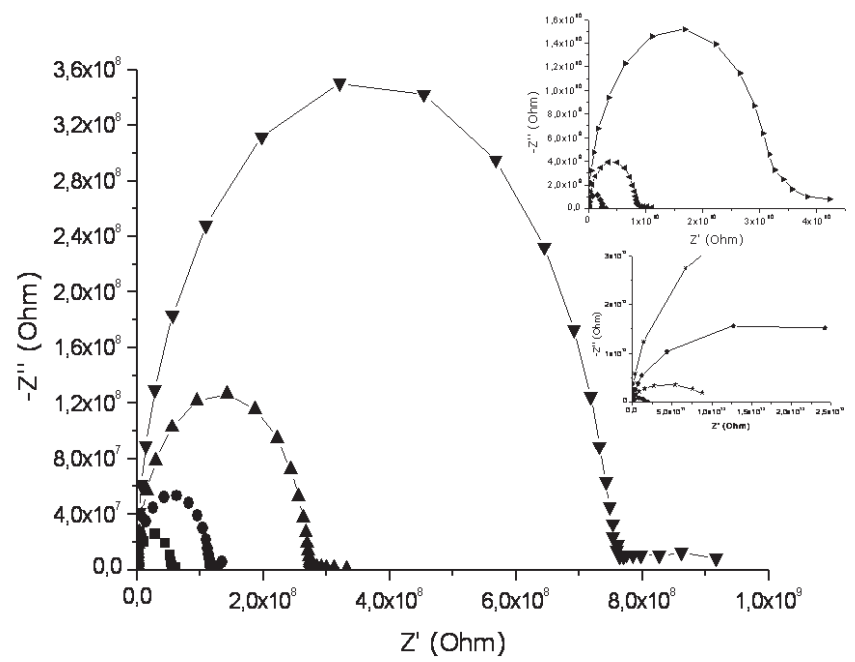

Fig. 11. Nyquist diagrams for $\mathrm{KN10}\left(4, \mathrm{R}_{1}=\mathrm{CH}_{3}, \mathrm{R}_{2}=\mathrm{CH}_{3}, \mathrm{X}=\mathrm{NTf}_{2}\right)$ at all temperatures: (square) 398K, (circle) 388K, (up triangle) 378K, (down triangle) 368K, (diamond) 358K, (left triangle) 348K, (right triangle) 338K, (hexagon) 328K, (star) 318K, (pentagon) 308K and (plus) $298 \mathrm{~K}$.

At high temperatures, the isotherms are characterized by a plateau nearly independent on frequency, followed by a dispersive regime. Moreover, whereas the plateau for the KN10 isotherms coexists with $\phi=0$ in a wide range of temperatures, this only occurs for the KN8 system at high temperatures. For low temperatures the values of $|\phi|$ at the frequencies studied are higher than zero, indicating that in these cases the ohmic resistance should be 
slightly higher than the maximum value of $/ Z^{*}(\omega) /$ at the apparent plateau for the conductivity $/ \sigma^{*}(\omega) /$. Then obtaining the whole Bode diagram would surely require measuring the impedance at frequencies significantly lower than those used in this study.

Similar results we can found from the study of $Z^{\prime \prime}$ vs. $Z^{\prime}$ plot, called Nyquist diagram ${ }^{27}$ such is observed in Figure 11 for KN10 at all temperatures. This Figure gives curves that intersect the abscissa axis at $Z^{\prime}=R_{0}$ and $Z^{\prime}=R_{0}+R_{p}$, when $w \rightarrow \infty$ and $w \rightarrow 0$, respectively. Departure from semicircles is observed in experimental Nyquist diagrams ${ }^{27}$ as a result of polarization processes and other phenomena taking place in the membrane electrode interface.

From Figures 9 and 10 we can see that the length of the plateau in the Bode diagrams increases as temperature increases until a critical frequency $f_{c}\left(=\omega_{c} / 2 \pi\right)$ dependent on temperature is reached, at which $\log / \sigma^{*}(\omega /$ collapses along a straight line with slope $d \log / Z^{*}\left(\omega / / d \log \omega=1\right.$. This is a typical behavior of a parallel $\mathrm{R}_{0} \mathrm{C}$ circuit, where at high frequencies at which $\omega C>>1$ and

$$
\lim _{\omega \rightarrow \infty} \log \left|\sigma^{*}(\omega)\right|=\lim _{\omega \rightarrow \infty} \log \left|\frac{1+j \omega R_{0} C}{R_{0}}\right| \cong \log (C \omega)
$$

And for low frequencies at which $\omega C<<1$, then $\lim _{\omega \rightarrow 0}\left|\sigma^{*}(\omega)\right|=1 / R_{0}$.

Thus for frequencies $\omega \leq 1 /\left(R_{p} C\right)$, the modulus of the complex impedance decreases from $R_{o}+$ $R_{p}$ at low frequencies to $R_{o}$ at high frequencies (i.e. the modulus of the complex conductivity increases from $1 /\left(R_{o}+R_{p}\right)$ at low frequencies to $1 / R_{o}$ at high frequencies). As indicated above, the detection of this drop in the modulus would require performing impedance experiments at very low frequencies. At the same time, the phase angle increases from $-90^{\circ}$ to $0^{\circ}$. However above the critical frequency $\omega_{c} \geq 1 /(\operatorname{RoC})$, the impedance is eminently capacitive and $\left|\sigma^{*}(\omega)\right| \propto \omega^{n}(\mathrm{n} \cong 1)$, in agreement with the results shown in the Bode diagrams of Figures 9 and 10. The critical frequency was taken as that one corresponding to the inflexion point of the phase angle, i.e. $\phi=-45^{\circ}$, at the temperature of interest. The plots of Figure 12 show that $f_{c}$ follows Arrhenius behavior. The plots of Figure 12 show that $f_{c}$ follows Arrhenius behavior with activation energies of (28.0 \pm 0.5$),(26.4 \pm 0.4),(16.2 \pm 0.3)$, (20.5 $\pm 1.0 .3),(26.2 \pm 0.7)$ and (25.7 \pm 0.6$) \mathrm{kcal} \mathrm{mol}^{-1}$ for KN5, KN6, KN7, KN8, KN9 and KN10, respectively.

The conductivity patterns showed in Bode diagrams of Figures 9 and 10 shown a similar ac conductivity patterns with a frequency independent plateau in the low frequency region and exhibits dispersion at higher frequencies 28 . The effect of electrode polarization is evidenced small deviation from the modulus of the conductivity (plateau region) value in the conductivity spectrum. For the SILLPs studied, the geometric capacitors obtained from eq. (6) is independent on temperature. The values of these capacitors are 1.48, 1.67, 1.07, 1.55, 2.30, and $2.56 p F$ for KN5, KN6, KN7, KN8, KN9 and KN10, respectively.

The ionic conductivity thus estimated for KN5 and KN6 are $4.0 \times 10^{-11} \mathrm{~S} / \mathrm{cm}$, at $358 \mathrm{~K}\left(85^{\circ} \mathrm{C}\right)$, to ca. $1.1 \times 10^{-9} \mathrm{~S} / \mathrm{cm}$ at $398 \mathrm{~K}\left(125^{\circ} \mathrm{C}\right)$ for $\mathrm{KN} 5$, and $3.3 \times 10^{-9} \mathrm{~S} / \mathrm{cm}$ to $1.4 \times 10^{-7} \mathrm{~S} / \mathrm{cm}$ for KN6 at the same temperatures. The conductivities of KN7 and KN9 are rather low increasing in the former material from $4.9 \times 10^{-12} \mathrm{~S} / \mathrm{cm}$, at $328 \mathrm{~K}\left(55^{\circ} \mathrm{C}\right)$, to ca. $1.4 \times 10^{-9} \mathrm{~S} / \mathrm{cm}$, at $398 \mathrm{~K}\left(125^{\circ}\right.$ C), S/cm, whereas in the SILLP KN9 the increase is from $8.5 \times 10^{-10}$ to $5.3 \times 10^{-7} \mathrm{~S} / \mathrm{cm}$, in the same range of temperature. Whereas the comparison of the ionic conductivity between KN8 and $\mathrm{KN} 10$ is estimated to change from $1.1 \times 10^{-11} \mathrm{~S} / \mathrm{cm}$, at $328 \mathrm{~K}\left(55^{\circ} \mathrm{C}\right)$, to ca. $2.1 \times 10^{-9}$ 


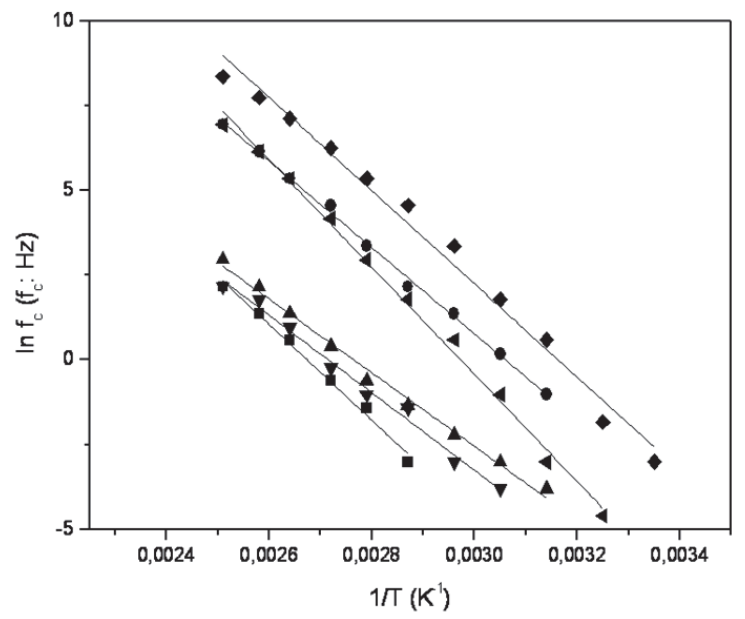

Fig. 12. Variation of the critical frequency $f_{c}$ at which the capacitance governs the impedance behaviour of the SILLPs at high frequencies: KN5 (squares), KN6 (circles), KN7 (up triangle), KN8 (down triangle), KN9 (diamond) and KN10 (left triangle).

$\mathrm{S} / \mathrm{cm}$, at $398 \mathrm{~K}\left(125^{\circ} \mathrm{C}\right), \mathrm{S} / \mathrm{cm}$ for $\mathrm{KN} 8$, while for the material $\mathrm{KN} 10$ the increase is from $7.9 \times$ $10^{-10}$ at $303 \mathrm{~K}\left(35^{\circ} \mathrm{C}\right)$ to $2.3 \times 10^{-7} \mathrm{~S} / \mathrm{cm}$ at $398 \mathrm{~K}\left(125^{\circ} \mathrm{C}\right)$. As shown in Figure 13 , the temperature dependence of the conductivity is also a thermally activated process described by the Arrhenius equation.

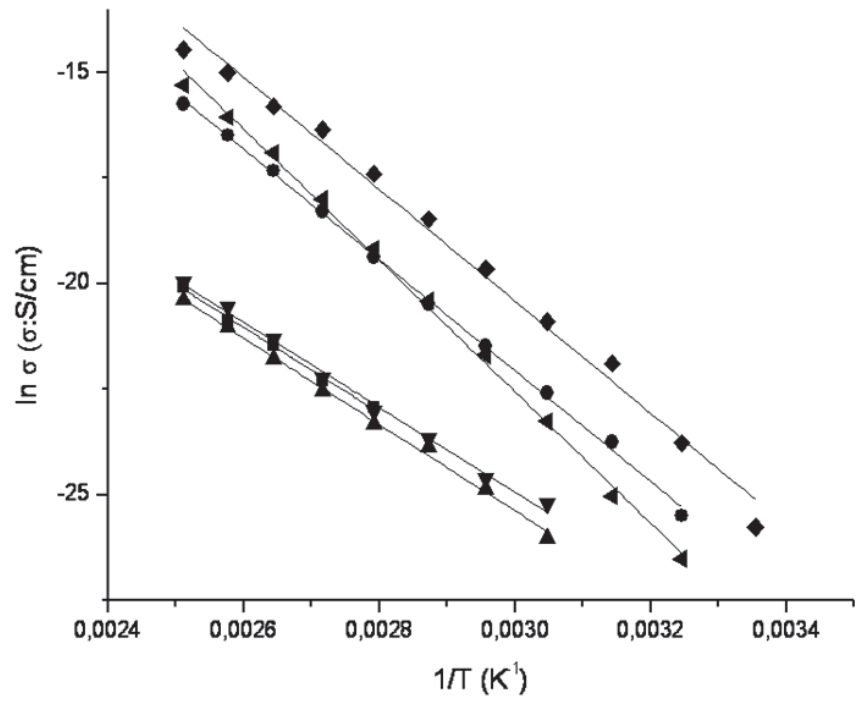

Fig. 13. Arrhenius Plot showing the temperature dependence of the conductivity of the SILLPs KN5 (squares), KN6 (circles), KN7 (up triangle), KN8 (down triangles), KN9 (diamonds) and KN10(left triangles). 
The ionic conductivity of KN6, KN9 and KN10 is nearly two orders of magnitude higher than that of KN5, KN7 and KN8, respectively, whatever temperature as a basis of comparison is taken. In principle, one could think that ionic transport in the materials is carried out by the mobile anions. In this case, the results suggest that the mobility of $\mathrm{NTf}_{2}$ - is higher than that of $\mathrm{Cl}^{-}$, a result opposite to what one at first sight would expect if the anions volume were determinant in the conductive process. However, strong coulombic forces between cations and anions in absence of humidity, makes this transport mechanism unlikely. Moreover, charge transport by anions would be dependent on frequency. Therefore, to explain the conductivity of these materials it is necessary to postulate charge delocalization between cations and anions as mainly responsible for the conductivity independent of frequency that KN5, KN6, KN7, KN8, KN9 and KN10 exhibit. Owing to the high electronegativity of the chloride anion, charge delocalization is obviously easier for $\mathrm{NTf}_{2^{-}}$than for $\mathrm{Cl}^{-}$and hence the higher conductivity of KN6, KN9 and KN10. Similar behavior and results have been found for other supported ionic liquid-like phases prepared by anchoring imidazolium moieties onto highly crosslinked poly(p-chloromethylstyrenecodivinylbenzene) monolithic matrices such as polymers KN7 and KN10.29 It is noteworthy that a similar effect is observed for both couples KN5/KN6, KN7/KN9 and KN8/KN10, the second one having a methyl substituent at the $\mathrm{C} 2$ position of the imidazolium ring. The change in the nature of the anion can be responsible for changing the conductivity observed by several orders of magnitude. On the contrary, changes on the structure of the cation are accompanied by observable modifications in conductivity, but always within the same order of magnitude. This suggests, for instance, that the interaction $\mathrm{C} 2-\mathrm{H} \leftarrow \mathrm{X}$ - is not the main factor for determining the conductivity of the SILLPs considered for the SILLPs here considered. Nevertheless, for $\mathrm{T}>\mathrm{Tg}$, an increase in temperature increases the mobility of the chains, facilitating charge delocalization between neighboring cations and anions.

\section{Analysis from dielectric complex permittivity}

The current intensity across a capacitor produced by the alternating voltage $V=V_{0} \operatorname{Im} \exp (j \omega t)$ is $i=(d q / d t)=j \omega C_{0} \varepsilon^{*}(\omega) V$ where $\omega$ is the frequency of the field, where $q$ is the positive charge at the electrodes, $C_{0}$ is the capacity of the capacitor in vacuum and $\varepsilon^{*}$ is the relative complex dielectric permittivity of the material that acts as dielectric of the capacitor. Since the ratio $i / V$ is a complex admittance or the reciprocal of the complex impedance, the complex permittivity of a material placed as dielectric between parallel arm plats is $\varepsilon^{*}(\omega)=l /\left(j \omega e_{0} S Z^{*}\right)$ where $e_{0}$ is the dielectric permittivity in vacuum whereas $S$ and $l$ are, respectively, the area and the thickness of the dielectric placed between the electrodes. Illustrative experimental isotherms showing the components of the complex dielectric permittivity in the frequency domain for KN6 and KN10 are presented at several temperatures in Figures 14 and 15, respectively. For temperatures lower than $328 \mathrm{~K}\left(55^{\circ} \mathrm{C}\right)$ for $\mathrm{KN} 6$ and $348 \mathrm{~K}\left(75^{\circ} \mathrm{C}\right)$ for $\mathrm{KN} 10, \varepsilon^{\prime}$ is only slightly dependent on frequency in the range $0.01 \leq f \leq 10^{6} \mathrm{~Hz}$. Identical behavior has been observed for the comparison between the others SILLPs. At higher temperatures, $\varepsilon^{\prime}$ undergoes a significant increase as frequency decreases, the increase being higher with temperature. This augment of $\varepsilon^{\prime}$ is the result of the enhancement on the mobility of the chains occurring when the systems surpass the glass transition temperature. However, the plateau exhibited by the real component of $\varepsilon^{*}$ at low 
frequencies in polar polymers is not reached in the SILLPs in the range of temperatures studied. 25,30

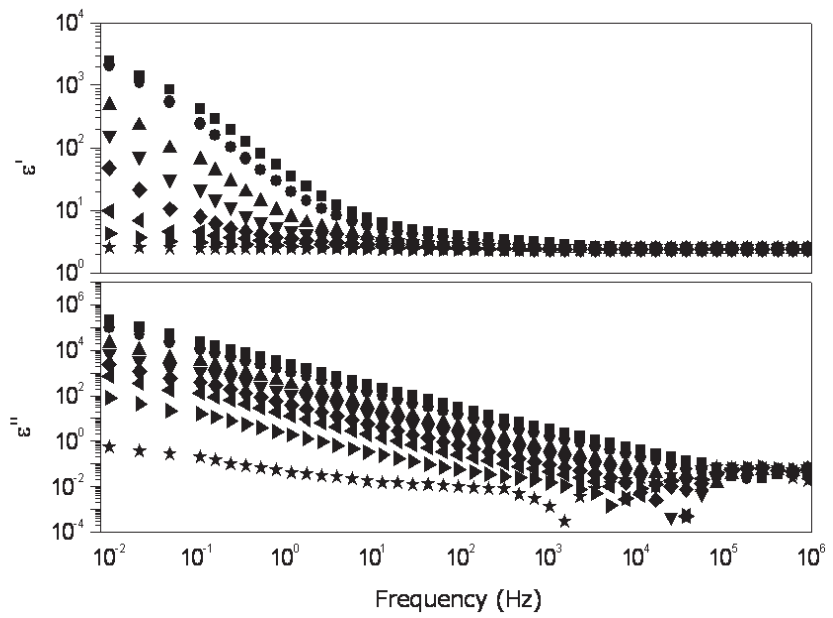

Fig. 14. Real (top) and loss (bottom) components of the complex dielectric permittivity for KN6 at several temperatures: (square) 398K, (circle) 388K, (up triangle) 378K, (down triangle) 368K, (diamond) 358K, (left triangle) 348K, (right triangle) 338K, (hexagon) 328K, (star) 318K, (pentagon) $308 \mathrm{~K}$ and (plus) $298 \mathrm{~K}$.
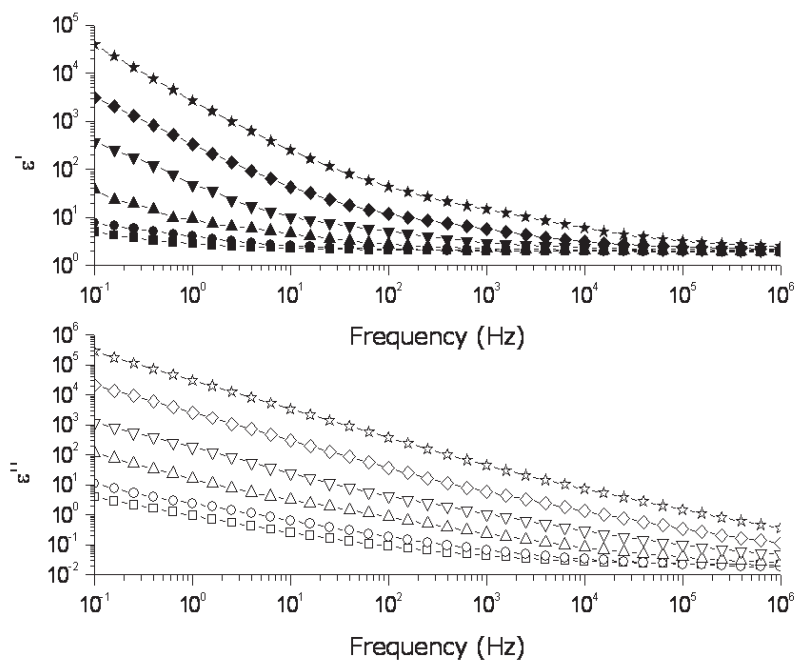

Fig. 15. Real (top) and loss (bottom) components of the complex dielectric permittivity for KN10 at several temperatures: (square) 398K, (circle) 388K, (up triangle) 378K, (down triangle) 368K, (diamond) 358K, (left triangle) 348K, (right triangle) 338K, (hexagon) 328K, (star) 318K, (pentagon) 308K and (plus) 298K. 
As for the dielectric loss, the isotherms present a dielectric dispersion in the high frequency region of the spectra, only detectable in the isotherms obtained at high temperature. At moderate and low frequencies $\varepsilon^{\prime \prime}$ is nearly a linear increasing function of the reciprocal of the frequency and as a result dielectric dispersions associated with the dielectric loss are obscured by the conductivity.

The permittivity loss shows a straight line at low frequencies with a slope close to -1 at high temperatures. In these polymers the presence of secondary relaxation of in the range of high frequencies can be observed. This relaxation of very low intensity presumably is due to the fact tha, the conductive processes present in the SILLPs are very important. The relaxation strength of these polymers was very low, minor than 0.10 for all SILLPs for the range of temperatures between $95 \mathrm{~K}$ and $125 \mathrm{~K}$ in all cases. To characterize the dipolar absorption at high temperatures, $\varepsilon_{d}^{\prime \prime}(\omega)$, the following equation (7) was used:31-33

$$
\varepsilon_{d}^{\prime \prime}(\omega)=\varepsilon^{\prime \prime}(\omega)-\left(\frac{\sigma}{\varepsilon_{0} \omega}\right)^{s}
$$

where $\sigma$ and $\varepsilon_{0}$ are the specific conductivity and the dielectric permittivity in vacuum $\left(=8.854 \mathrm{pFm}^{-1}\right)$, respectively, and $\mathrm{s} \leq 1$ is an exponent whose departure from the unit is caused by the interfacial electrode-sample process intervening in the $\alpha$-relaxation. In our study, the value of $s$ is compress between 0.80 and 0.99 depending on the temperature for all the SILLPs studied. The values of the conductivity obtained from the curves of permittivity loss by mean of equation (6) follow a Arrhenius behaviour. The values of the activation energies reach $(27.1 \pm 0.4),(23.4 \pm 1.0),(21.5 \pm 0.2),(21.1 \pm 0.2),(24.3 \pm 0.7)$ and $(30.3 \pm 0.4) \mathrm{kcal} / \mathrm{mol}$, for KN5, $\mathrm{KN} 6, \mathrm{KN} 7, \mathrm{KN} 8, \mathrm{KN} 9$ and KN10 respectively. The main purpose of this chapter is not to characterize the dipolar relaxations that this SILLPs can have at high frequencies. We are essentially focused on the study of the conductivity of the SILLPs. Nevertheless, a few comments should be made before discussing the dielectric relaxation behaviour of the SILLPS. The high crosslinking degree of the supporting material, as well as the strong intermolecular interactions between the ionic groups should enhance the glass transition temperature of the SILLPS in such a way that, in principle, the magnitude of this parameter should be higher than $373 \mathrm{~K}$, the $\mathrm{Tg}$ of polystyrene. Then the ostensible glass-rubber relaxation that uncrosslinked polar polymers present, should be absent in the dielectric relaxation spectra of the SILLPs. However, the abrupt changes occurring in $\varepsilon^{\prime}$ at temperatures slightly above $348 \mathrm{~K}$ for KN5, KN7 and KN8, and above of $328 \mathrm{~K}$ for KN6, $\mathrm{KN} 9$ and $\mathrm{KN} 10$, are the result of the glass-rubber relaxation taking place in the vicinity of these temperatures. The glass rubber relaxation in these apparently highly crosslinked systems may arise from the morphology of the crosslinked SILLPs. Owing to the high chemical reactivity of divinyl benzene, which is nearly four times that of styrene, ${ }^{34}$ a gel with a nucleus of moderately crosslinked poly(dvinyl benzene) chains containing occasional chloromethyl styrene units may be firstly formed. As the crosslinking reaction proceeds, the $\mathrm{Tg}$ of the gel increases approaching to the reaction temperature, and the overall polymerization rate diminishes because the diffusivity of the reacting monomers to the growing radicals decreases. The remnant $p$-chloromethylstyrene may graft to the unreacted double bonds of divinyl benzene, forming dangling chains, responsible for the glass transition displayed by these systems at relatively low temperature. 


\section{Analysis of the conductivity from electric modulus formalism}

When discussing the results presented in Figures 14 and 15, we have noted that the dielectric permittivity $\varepsilon^{\prime \prime}$ strongly increases with temperature in the low frequency region, which we attributed to a conduction process. In order to explore this phenomenon in detail, the electric modulus formalism $\mathrm{M}^{*}$ has been widely used.35-36

Despite some doubts cast on the applicability of the method for this task, 37,38 a combined study of ionic motion using electrical relaxation and RMN relaxations suggests that the complex modulus is the most appropriate representation of dielectric data for analysis of ionic conductivity relaxation as in the present case. The points made by Elliot ${ }^{37}$ and Roling 38 as well by others authors to discredit the dielectric modulus representation have been refuted and are summarily discussed in a review article, where the authors have answered all the unnecessary criticism on the use of the electric modulus. ${ }^{39}$ The representation of the macroscopic data to describe the microscopic motion of the movement of the ions has been also well described, as in the present case, by Ngai et al. 40

The electric modulus is the reciprocal of the permittivity $M^{*}=1 / \varepsilon^{*}$. Generally, for a pure conduction process, a relaxation peak would be observed in the frequency spectra of the imaginary component $\mathrm{M}^{\prime \prime}$ and no peak would take place in the corresponding plot of $\varepsilon^{\prime \prime}$, such is our case in all the SILLPs.

Isotherms at several temperatures showing the double logarithmic plots of the real and imaginary components of the complex dielectric modulus of KN6, are shown in the frequency domain in Figure 16. As occurs with the modulus of relaxation processes, $M^{\prime}$ increases as the frequency increases until a frequency is reached at which $M^{\prime}$ remains nearly constant. Moreover $M^{\prime \prime}$ displays at low frequencies the characteristic absorption of conductive processes and a $\mathrm{M}^{\prime \prime}$ peak in the plots $\mathrm{M}^{\prime \prime}$ vs. frequency is observed in relation to conductivity relaxation of the SILLPs. In addition to the conduction peak, it can be seen in some cases at high temperatures a second peak which shift to higher frequency with a very small absorption. ${ }^{29}$ These peaks indicate the transition from short range to long range mobility with decreasing frequency, where the low frequency side of the peak represents moving long distances, i.e., performing successful hopping from one site to the neighboring site, whereas, for the high frequency side, the ions are spatially confined to their potential wells and can execute only localized motion. ${ }^{11,42}$

The relaxation of the dielectric modulus can be mathematically represented equivalently as a function of time or of frequency. This approach developed for a single relaxation time for dielectric relaxations by Debye has been extended by Havriliak and Negami to a distribution of relaxation times. 43 The frequency representation for the complex modulus as found by the empirical Havriliak-Negami model function as ${ }^{44}$

$$
M^{*}(\omega)=M_{\infty}+\frac{M_{0}-M_{\infty}}{\left[1+\left(j \omega \tau_{H N}\right)^{\alpha}\right]^{\beta}}
$$

where $\mathrm{M}_{\infty}$ and $\mathrm{M}_{0}$ are the unrelaxed and relaxed moduli, $\omega$ is the excitation frequency and $\tau_{\mathrm{HN}}$ is the average relaxation time. The parameter $\alpha(0<\alpha<1)$ broadens the width of the relaxation as it decreases in value; the parameter $\beta(0<\beta<1)$ causes a skewing or asymmetry in the modulus in both real and imaginary parts as a function of frequency. 


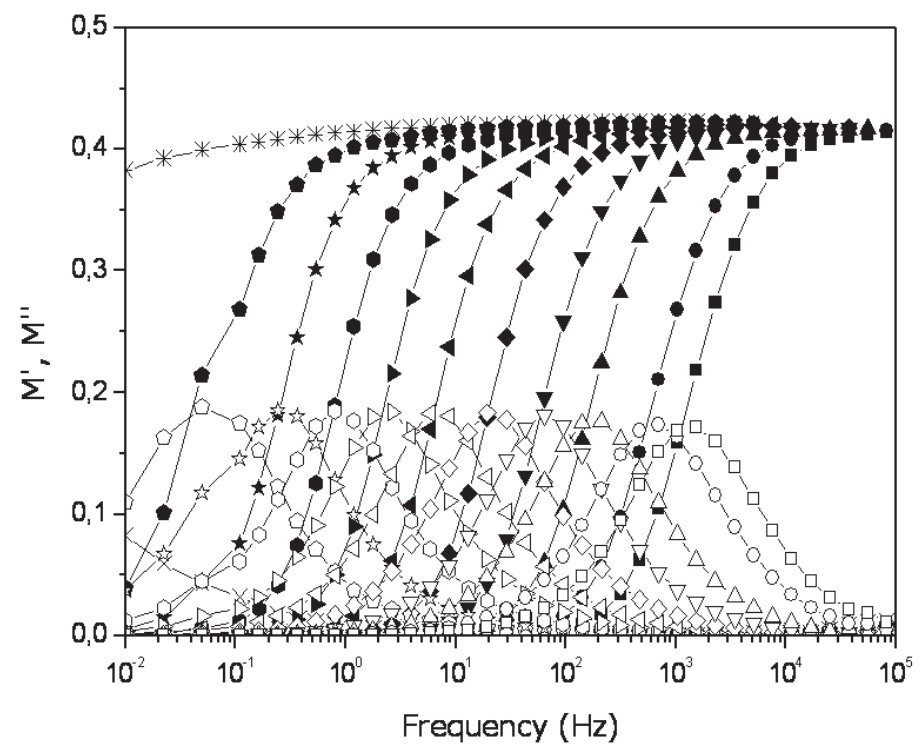

Fig. 16. Components of the complex dielectric modulus in the frequency domain for KN6 at several temperatures: (square) 398K, (circle) 388K, (up triangle) 378K, (down triangle) 368K, (diamond) 358K, (left triangle) 348K, (right triangle) 338K, (hexagon) 328K, (star) 318K, (pentagon) $308 \mathrm{~K}$ and (plus) 298K; solid symbols for real dielectric modulus component and open symbols for loss dielectric modulus component.

In table 2 are given the parameters of the fitting the loss peak observed in Figure 16, for $\mathrm{M}^{\prime \prime}(\mathrm{w})$ spectra by mean of the HN equation for the KN6. In the same table, we also give the results obtained for the other SILLPs. The skewed form of the curves proceeds from ion-ion interactions and the high values of the $\beta_{\mathrm{HN}}$ parameter suggest the absence of those interactions because of the combined effect of the relatively low concentration of ionic species in those materials and the rigidity of the polymeric matrix that hinders ion-ion interactions. Actually, a second parameter that is in good agreement with this reasoning can be obtained from the full width at half maximum of the $\mathrm{M}^{\prime \prime}$ peak in Figure 16. The value of this parameter for KN5, KN6, KN7, KN8, KN9 and KN10 is 1.4, 1.3, 1.3, 1.4, 1.2 and 1.2, respectively, and it is higher than the one corresponding to a single Debye peak (1.144) This suggest that the conductive peak includes not only pure ionic contributions but also electrodes polarization effects. It has been proven before that ion-ion interaction contributes to the width of the loss peak. 45

The $f_{\max }$ is the frequency at which $M^{\prime \prime}(f)$ reach the maximum value and $\tau_{\max }=1 / 2 \pi f_{\max }$, where the ratio between $\tau_{\max }$ and $\tau_{\mathrm{HN}}$ is defined by the equation ${ }^{46}$

$$
\tau_{\max }=\tau_{H N}\left[\frac{\sin \left(\frac{\pi\left(\alpha_{H N}\right) \beta_{H N}}{2\left(\beta_{H N}+1\right)}\right)}{\sin \left(\frac{\pi\left(\alpha_{H N}\right)}{2\left(\beta_{H N}+1\right)}\right)}\right]^{\frac{1}{\alpha_{H N}}}
$$


In Figure 17 we have plotted the dependence of $\mathrm{f}_{\max }=1 / 2 \pi \tau_{\max }$ (characteristic relaxation times of the modulus) obtained for KN5, KN6, KN7, KN8, KN9 and KN10 in the form of a Arrhenius plot. The variation of the dielectric loss modulus with temperature in the low frequency region obeys the Arrhenius behavior with activation energies of $(22.8 \pm 0.7)$, $(27.8 \pm 0.6),(20,4 \pm 0,4),(18,9 \pm 0,7),(25,1 \pm 0,5)$, and $(28,5 \pm 0,5), \mathrm{kcal} / \mathrm{mol}$ for KN5, KN6, KN7, KN8, KN9 and KN10, respectively. A comparison between this values and the obtained from the conductivity calculated from the loss permittivity and from Bode diagram are in complete agreement, and on the other hand, these values are nearly similar to those obtained before in the analysis of the ionic conductivity by impedance spectroscopy indicating that ionic transport in the SILLPs is the origin of them. In the imaginary part of the modulus spectra a relaxation peak is observed for all the SILLPs for the conductivity processes of different intensity. The intensity of the modulus relaxation peak is $0.18,0.19$, $0.16,0.23,0.22$ and 0.15 , for KN5, KN6, KN7, KN8, KN9 and KN10, respectively; whereas no peak is observed in the dielectric spectra. Similar results have been reported by Fu et al. ${ }^{47}$ for PPG-LiCF $3 \mathrm{SO}_{3}$ system with higher salt concentration. So the conduction in polymer electrolytes takes place through charge migration of ions between coordinated sites of the polymer along with its segmental relaxation.

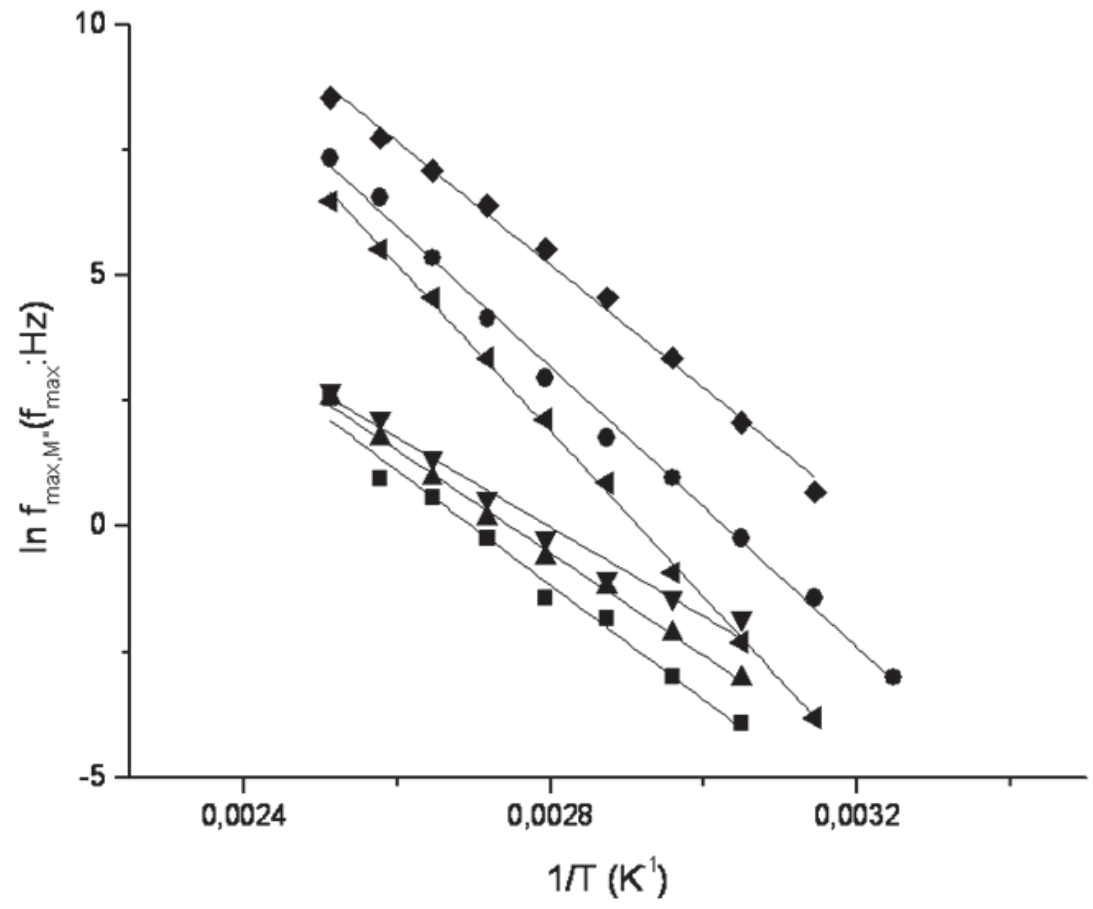

Fig. 17. Arrhenius behaviour of conduction relaxation times for the main dielectric mechanisms recorded in the SILLPs: KN5 (squares), KN6 (circles), KN7 (up triangles), KN8 (down triangles), KN9 (diamonds) and KN10 (left triangles). 
For many ionically conducting materials, the $\mathrm{M}^{\prime \prime}(f)$ curves exhibit skewed shapes and, as a result, the complex dielectric modulus can be expressed in terms of the Laplace transform of the decay Kohlrausch-Williams-Watts (KWW) relaxation function. ${ }^{48,49}$ The fit of the loss peak given at low frequencies for $\mathrm{M}^{\prime \prime}(\mathrm{w})$ spectra to the Fourier transform of the KohlrauschWilliams-Watts (KWW) function ${ }^{50}$ the values obtained for $\beta_{\mathrm{KWW}}$ of the samples KN5 and $\mathrm{KN} 6$ are respectively, ${ }^{29} \beta_{\mathrm{KWw}}=0.77$ and 0.78 at $398 \mathrm{~K}$. The skewed form of the curves proceeds from ion-ion interactions and the high values of $\beta_{\mathrm{Kww}}$ parameter suggests absence of these interactions as consequence of the combined effect of the relatively low concentration of ionic species in these materials and the rigidity of the polymeric matrix that hinder ion-ion interactions. Also the crosslinks will inhomogeneously broaden the peak and to make it symmetrical. Actually another fact that can justify this can be taken from the full width at half maximum of the $\mathrm{M}^{\prime \prime}$ peak in Figure 18 for KN5 and KN6 it is about 1.5 decade at $338 \mathrm{~K}\left(65^{\circ} \mathrm{C}\right), 368 \mathrm{~K}\left(95^{\circ} \mathrm{C}\right)$ and $398 \mathrm{~K}\left(125^{\circ} \mathrm{C}\right)$, respectively. The agreement between the experimental data and the fitting curves (solid lines) is very good. From the values showed in table 2 we can observe that $\alpha$ and $\beta$ values from both frequency and time domains, for all the SILLPs, are not dependent on temperature. A similar behavior has been reported by Alvarez et al. for poly(hydroxyl ether of bisphenol-A) polymers. ${ }^{51}$
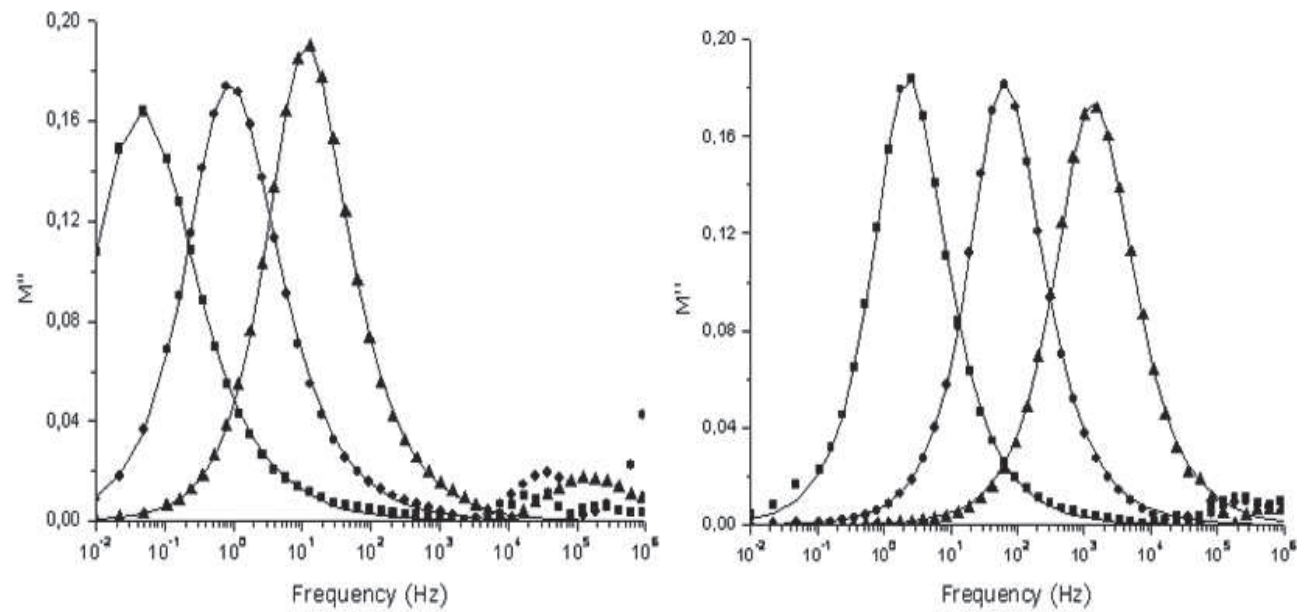

Fig. 18. Isothermal loss modulus peaks curves and their fits to the Havriliak-Negami expression at 338K (right triangles), 368K (down triangles) and $398 \mathrm{~K}$ (squares), respectively. Left: KN5; Rigth: KN6.

The lack of ion-ion interactions is also made evident in the fact that the conductivity of SILLPs are a thermally activated process, whereas in the case of supercooled ionic liquids with high ion-ion interactions the variation of the conductivity are governed by the volume. ${ }^{2}$ At high frequencies, the secondary absorptions arising from local motions of moieties involving the imidazolium group which presumably arise from rotations about the Car- $\mathrm{CH}_{2}-\mathrm{N}$ bonds of the ILs moieties, are affected by the nature of the counterion. 


\begin{tabular}{|c|c|c|c|c|c|c|}
\hline $\mathrm{T}$ & KN5 & KN6 & KN 7 & KN8 & KN9 & KN10 \\
\hline$(\mathrm{K})$ & $\begin{array}{l}10^{10} \times \sigma \\
\mathrm{S} / \mathrm{cm}\end{array}$ & $\begin{array}{l}10^{8} \times \sigma \\
\mathrm{S} / \mathrm{cm}\end{array}$ & $\begin{array}{l}10^{10} \times \sigma \\
\mathrm{S} / \mathrm{cm}\end{array}$ & $\begin{array}{l}10^{10} \times \sigma \\
\mathrm{S} / \mathrm{cm}\end{array}$ & $\begin{array}{l}10^{8} \times \sigma \\
\mathrm{S} / \mathrm{cm}\end{array}$ & $\begin{array}{l}10^{8} \times \sigma \\
\mathrm{S} / \mathrm{cm}\end{array}$ \\
\hline 398 & 19.0 & 14.5 & 14.0 & 21.3 & 53.0 & 22.8 \\
\hline 388 & 8.6 & 7.0 & 7.4 & 11.8 & 30.8 & 10.6 \\
\hline 378 & 4.8 & 3.0 & 3.5 & 5.6 & 13.8 & 4.6 \\
\hline 368 & 2.1 & 1.1 & 1.6 & 2.2 & 8.0 & 1.5 \\
\hline 358 & 1.1 & 0.39 & 0.74 & 1.0 & 2.8 & 0.47 \\
\hline 348 & 0.16 & 0.13 & 0.43 & 0.52 & 0.95 & 0.14 \\
\hline 338 & - & 0.05 & 0.16 & 0.20 & 0.29 & 0.038 \\
\hline 328 & - & 0.016 & 0.05 & 0.11 & 0.085 & 0.079 \\
\hline 318 & - & 0.005 & - & - & 0.031 & 0.013 \\
\hline 308 & - & 0.0008 & - & - & 0.0047 & 0.0003 \\
\hline 298 & - & - & - & - & - & - \\
\hline $\begin{array}{c}\mathrm{E}_{\mathrm{act}} \\
\mathrm{Kcal} / \mathrm{mol}\end{array}$ & $20.2 \pm 0.4$ & $26.2 \pm 0.4$ & $17.2 \pm 0.2$ & $17.0 \pm 0.2$ & $26.5 \pm 0.5$ & $29.4 \pm 0.6$ \\
\hline
\end{tabular}

Table 1. Conductivities and activation energies for the KN5, KN6, KN7, KN8, KN9 and KN10 SILLPs obtained from the plateau of the Bode diagrams.

\begin{tabular}{|c|c|c|c|c|c|c|c|}
\hline SILLPs & $\begin{array}{c}\text { Temperature } \\
\text { (K) }\end{array}$ & $\Delta \mathrm{M}$ & $\alpha$ & $\beta$ & $\begin{array}{l}\text { Max. } \\
\text { Width }\end{array}$ & $\begin{array}{c}\tau_{\mathrm{HN}} \\
(\mathrm{s})\end{array}$ & $\begin{array}{c}\tau_{\max } \\
(\mathrm{s})\end{array}$ \\
\hline \multicolumn{8}{|c|}{ KN5 } \\
\hline & 328 & 0.41 & 1.0 & 0.58 & 1.48 & 11.5 & 7.4 \\
\hline & 338 & 0.5 & 0.81 & 0.77 & 1.74 & 4.5 & 3.4 \\
\hline & 348 & 0.50 & 0.80 & 0.80 & 1.73 & 1.5 & 1.2 \\
\hline & 358 & 0.49 & 0.83 & 0.80 & 1.67 & 0.57 & 0.45 \\
\hline & 368 & 0.49 & 0.86 & 0.78 & 1.60 & 0.23 & 0.18 \\
\hline & 378 & 0.48 & 0.89 & 0.77 & 1.54 & 0.09 & 0.07 \\
\hline & 388 & 0.48 & 0.99 & 0.76 & 1.31 & 0.06 & 0.05 \\
\hline & 398 & 0.48 & 0.93 & 0.77 & 1.43 & 0.02 & 0.01 \\
\hline \multicolumn{8}{|c|}{ KN6 } \\
\hline & 328 & 0.39 & 0.88 & 0.68 & 1.65 & 1.47 & 1.02 \\
\hline & 338 & 0.51 & 0.73 & 0.89 & 1.91 & 1.34 & 1.16 \\
\hline & 348 & 0.48 & 0.83 & 0.77 & 1.68 & 0.78 & 0.60 \\
\hline & 358 & 0.47 & 0.88 & 0.71 & 1.59 & 0.37 & 0.27 \\
\hline & 368 & 0.46 & 0.87 & 0.75 & 1.59 & 0.15 & 0.11 \\
\hline & 378 & 0.46 & 0.90 & 0.71 & 1.5 & 0.07 & 0.05 \\
\hline & 388 & 0.46 & 0.90 & $0, .72$ & 1.54 & 0.03 & 0.02 \\
\hline & 398 & 0.46 & 0.90 & 0.71 & 1.53 & 0.02 & 0.01 \\
\hline
\end{tabular}




\begin{tabular}{|c|c|c|c|c|c|c|c|}
\hline SILLPs & $\begin{array}{c}\text { Temperature } \\
(\mathrm{K})\end{array}$ & $\Delta \mathrm{M}$ & $\alpha$ & $\beta$ & $\begin{array}{l}\text { Max. } \\
\text { Width }\end{array}$ & $\begin{array}{c}\tau_{\mathrm{HN}} \\
(\mathrm{s})\end{array}$ & $\begin{array}{c}\tau_{\max } \\
(\mathrm{s})\end{array}$ \\
\hline \multicolumn{8}{|c|}{ KN7 } \\
\hline & 328 & 0.39 & 0.88 & 0.68 & 1.70 & 1.47 & 1.0200 \\
\hline & 338 & 0.51 & 0.72 & 0.88 & 1.90 & 1.34 & 1.1562 \\
\hline & 348 & 0.48 & 0.83 & 0.77 & 1.70 & 0.78 & 0.5954 \\
\hline & 358 & 0.47 & 0.88 & 0.71 & 1.60 & 0.37 & 0.2712 \\
\hline & 368 & 0.46 & 0.87 & 0.75 & 1.60 & 0.15 & 0.1133 \\
\hline & 378 & 0.46 & 0.90 & 0.72 & 1.50 & 0.07 & 0.0530 \\
\hline & 388 & 0.46 & 0.90 & 0.72 & 1.50 & 0.03 & 0.0246 \\
\hline & 398 & 0.46 & 0.90 & 0.72 & 1.50 & 0.017 & 0.0125 \\
\hline \multicolumn{8}{|c|}{ KN8 } \\
\hline & 328 & 0.67 & 0.84 & 0.77 & 1.4 & 1.4 & 0.135 \\
\hline & 338 & 0.59 & 0.92 & 0.77 & 1.3 & 1.01 & 0.988 \\
\hline & 348 & 0.54 & 0.94 & 0.77 & 1.25 & 0.55 & 0.52 \\
\hline & 358 & 0.53 & 0.98 & 0.77 & 1.24 & 0.254 & 0.24 \\
\hline & 368 & 0.52 & 1 & 0.75 & 1.24 & 0.119 & 0.108 \\
\hline & 378 & 0.52 & 1 & 0.77 & 1.24 & 0.05 & 0.046 \\
\hline & 388 & 0.52 & 1 & 0.76 & 1.25 & 0.025 & 0.023 \\
\hline & 398 & 0.51 & 1 & 0.77 & 1.25 & 0.0128 & 0.012 \\
\hline \multicolumn{8}{|c|}{ KN9 } \\
\hline & 328 & 0.44 & 1 & 0.88 & 1.21 & 0.36 & 0.33 \\
\hline & 338 & 0.44 & 0.93 & 0.93 & 1.33 & 0.089 & 0.08 \\
\hline & 348 & 0.48 & 1 & 0.82 & 1.25 & 0.025 & 0.02 \\
\hline & 358 & 0.48 & 1 & 0.83 & 1.24 & 0.0067 & 0.0058 \\
\hline & 368 & 0.48 & 1 & 0.82 & 1.25 & 0.002 & 0.0019 \\
\hline & 378 & 0.48 & 1 & 0.84 & 1.23 & 0.00077 & 0.00068 \\
\hline & 388 & 0.48 & 1 & 0.86 & 1.22 & 0.00031 & 0.00028 \\
\hline & 398 & 0.48 & 1 & 0.82 & 1.25 & 0.00016 & 0.00014 \\
\hline & 328 & 0.48 & 1 & 0.82 & 1.25 & 0.00008 & 0.000068 \\
\hline & 338 & 0.48 & 1 & 0.84 & 1.24 & 0.00004 & 0.000037 \\
\hline \multicolumn{8}{|c|}{ KN10 } \\
\hline & 328 & 0.33 & 0.98 & 0.82 & 1.29 & 0.460 & 0.39 \\
\hline & 338 & 0.32 & 0.98 & 0.85 & 1.26 & 0.090 & 0.08 \\
\hline & 348 & 0.32 & 0.99 & 0.85 & 1.25 & 0.024 & 0.021 \\
\hline & 358 & 0.32 & 0.99 & 0.84 & 1.24 & 0.007 & 0.006 \\
\hline
\end{tabular}




\begin{tabular}{|c|c|c|c|c|c|c|c|}
\hline SILLPs & $\begin{array}{c}\text { Temperature } \\
(\mathrm{K})\end{array}$ & $\Delta \mathrm{M}$ & $\alpha$ & $\beta$ & $\begin{array}{c}\text { Max. } \\
\text { Width }\end{array}$ & $\begin{array}{c}\tau_{\mathrm{HN}} \\
(\mathrm{s})\end{array}$ & $\begin{array}{c}\tau_{\max } \\
(\mathrm{s})\end{array}$ \\
\hline & 368 & 0.32 & 0.99 & 0.85 & 1.24 & 0.002 & 0.0018 \\
\hline & 378 & 0.32 & 0.99 & 0.86 & 1.24 & 0.0007 & 0.00065 \\
\hline & 388 & 0.32 & 0.99 & 0.85 & 1.25 & 0.0003 & 0.00028 \\
\hline & 398 & 0.32 & 0.99 & 0.85 & 1.25 & 0.00015 & 0.00013 \\
\hline
\end{tabular}

Table 2. Parameters obtained from fit to the experimental data by the empirical HavriliakNegami model function given by means of equation (8) for KN5, KN6, KN7, KN8, KN9 and KN10, respectively.

\section{Conclusions}

From the beginning, the study of bulk ILs has been associated with the development of new families of electrolytes. The reported needs for the preparation of new and efficient solid electrolytes was, on the other hand, at the origin of the preparation of polymeric species containing IL-like species. Up to now there has been a logical association between the preparation of linear polymeric SILLPs and their application as solid electrolytes. The high level of mobility that can be associated to those ionic materials, very often presenting low $\mathrm{Tg}$ values, makes reasonable this assumption. Nevertheless, the present results clearly highlight that SILLPs based on crosslinked polymeric matrices can also be of great interest in this field. The data obtained by different techniques reveal that preparation of polystyrenedivinylbenzene polymers containing imidazolium subunits is associated with the formation of polymeric surfaces to which most of the physico-chemical properties of the related bulk IL have been transferred. The modification of structural parameters in the cation, the methatesis of the anion or the variations in the loading of IL-like subunits are parameters that allow a simple modulation of the properties of the resulting SILLPs. Dielectric relaxation measurements have revealed the presence of an appreciable conductivity on those polymeric systems. A thorough theoretical analysis is possible from those experiments, being possible a complete characterization of those SILLPs as solid electrolytes. The analysis of the variation of the corresponding data with the structural modifications provides the potential for modeling the macroscopic structure for those functional polymeric surfaces, providing key information for many different applications considered for those materials. The proper understanding of the behavior of those crosslinked polymers as solid electrolytes opens the way for the design and preparation of new materials for electrical and electronic applications, in particular taking into consideration the porous morphology and the high level of structural variations available.

\section{Acknowledgments}

This work was supported by the Instituto de la Pequeña y Mediana Industria Valenciana (IMPIVA), Grant IMIDIC 2009/155. We thank the Spanish Ministerio de Ciencia y Tecnología (CTQ2008-04412/BQU and CTQ2008-04309/BQU) and Bancaixa-UJI (P1 1A200958) for financial support. 


\section{References}

[1] P. Wasserscheid, T. Welton, Ionic Liquids in Synthesis, Wiley-VCH, Weinheim, 2007; b) R. D. Rogers, G. A. Voth, Acc. Chem. Res. 2007, 40, Ionic Liquids special issue.

[2] N. Sun, H. Rodríguez, M. Rahman, R. D. Rogers, Chem. Commun., 2011, 47, 1405; b) M. Palacio, B. Bhushan, Tribol. Lett., 2010, 40, 247; c) N. V. Plechkova, K.R. Seddon, Chem. Soc. Rev., 2008, 37, 123.

[3] R. F. M. Frade, C. A. M. Afonso, Human and Experimental Toxicology, 2010, 29, 1038. b) T. P. Thuy Pham, C.-W. Cho, Y.-S. Yun, Water Research, 2010, 44, 352. c) D. Coleman, N. Gathergood, Chem. Soc. Rev., 2010, 39, 600.

[4] C. P. Mehnert, Chem. Eur. J., 2004, 11, 50; b) A. Riisager, R. Fehrmann, S. Flicker, R. van Hal, M. Haumann, P. Wasserscheid, Angew. Chem. Int. Ed., 2005, 44, 815; c) Y. Gu, G. Li, Adv. Synth. Catal., 2009, 351, 817; d) C. Van Doorslaer, J. Wahlen, P. Mertens, K. Binnemans, D. De Vos, Dalton Trans., 2010, 39, 8377.

[5] H. Olivier-Bourbigou, L. Magna, D. Morvan, Applied Catal. A, 2010, 373, 1; b) J. Dupont, R. F. De Souza, P. A. Z. Suarez, Chem. Rev., 2002, 102, 3667.

[6] a) P. Lozano, Green Chem., 2010, 12, 555; b) M. Moniruzzaman, K. Nakashima, N. Kamiya, M. Goto, Biochem. Eng. J., 2010, 48, 295.

[7] C. F. Poole, S. K. Poole, J. Chrom., 2010, 1217, 2268; b) H. Zhao, S. Xia, P. Ma, J. Chem. Tech. Biotech., 2005, 80, 1089.

[8] A. Stark, Energy Env. Science, 2011, 4, 19; b) A., Pinkert, K. N., Marsh, S. Pang, M. P.Staiger, Chem. Rev., 2009, 109, 6712.

[9] M. Armand, F. Endres, D. R. MacFarlane, H. Ohno, B. Scrosati, Nature Mat., 2009, 8, 621.

[10] N. Srivastava, T. Tiwari, E-Polymers, 2009, art. no. 146.

[11] H. Ohno, Bull. Chem. Soc. Jpn., 2006, 79, 1665.

[12] J. Yuan, M. Antonietti, Polymer, 2011, 52, 1469; b) M. D. Green, T. E. Long, Pol. Rev., 2009, 49, 291.

[13] K. Nakamura, T. Saiwaki, K. Fukao, Macromolecules, 2010, 43, 6092; b) M. Lee, U. H. Choi, R. H. Colby, H. W. Gibson, Chem. Mat., 2010, 22, 5814.

[14] N. Karbass, V. Sans, E. García-Verdugo, M. I. Burguete, S. V. Luis, Chem. Commun., 2006, 3095; b) P. Lozano, E. García-Verdugo, R. Piamtongkam, N. Karbass, T. DeDiego, M. I. Burguete, S. V. Luis, J. L. Iborra, Adv. Synth. Catal., 2007, 349, 1077; c) M. I. Burguete, H. Erythropel, E. García-Verdugo, S. V. Luis, V. Sans, Green Chem., 2008, 10, 401. d) M. I. Burguete, E. García-Verdugo, I. Garcia-Villar, F. Gelat, P. Licence, S. V. Luis, V. Sans, J. Catal., 2010, 269, 150; e) V. Sans, F. Gelat, N. Karbass, M. I. Burguete, E. García-Verdugo, S. V. Luis, Adv. Synth. Catal., 2010, 352, 3013.

[15] V. Sans, N. Karbass, M. I. Burguete, V. Compañ, E. García-Verdugo, S. V. Luis, M. Pawlak, Chem. Eur. J., 2011, 17, 1894.

[16] N. Meine, F. Benedito, R. Rinaldi, Green Chem., 2010, 12, 1711; b) H. L. Ngo, K. LeCompte, L. Hargens, A. B. McEwen, Thermochim. Acta., 2000, 357-358, 97; c) M. Koel, Proc. Estonian Acad. Sci. Chem.; 2000, 49, 145. d) K. J. Baranyai, 
G. B. Deacon, D. R. MacFarlane, J. M. Pringle, J. L. Scott, Aust. J. Chem. 2004, $57,145$.

[17] C. Chiappe, M. Malvaldi, C. S. Pomelli, Pure \& Appl. Chem., 2009, 81, 767.

[18] A. Nakajima, Spectrochim. Acta, 1974, 30A, 360. b) D. C. Dong, M. A. Winnik, Photochem. Photobiol., 1982, 35, 17. c) P. Lianos, S. Georghiou, Photochem. Photobiol., 1979, 30, 355.

[19] C. Reichardt, Solvent Effects in Organic Chemistry, Wiley-VCH, Weinheim, 3rd edn., 2003;

b) C. Reichardt, Chem. Soc. Rev. 1992, 21, 147, c) C. Reichardt, Chem. Rev. 1994, 94, 2319.

[20] C. Reichardt, Green Chem., 2005, 7, 339; b) S. V. Dzyuba, R. A. Bartsch, Tetrahedron Lett., 2002, 43, 4657.

[21] D. C. Dong, M. A. Winnik, Can. J. Chem, 1984, 62, 2560.

[22] K. A. Fletcher, I. A. Storey, A. E. Hendricks, S. Pandey, S. Pandey, Green Chem., 2001, 3, 210. b) D. S. Karpovich, G. J. Blanchard, J. Phys. Chem. 1995, 99, 3951.

[23] D. C. Sherrington, Chem Commun. 1998, 2275

[24] E. Riande, R. Diaz-Calleja, Electrical Properties of Polymers; Marcel Dekker: New York, 2004; chapter 8.

[25] J.R. MacDonald, Impedance Spectroscopy. Emphasizing solid materials and systems, Chapter 2, pp. 87-88. Wiley-Interscience, 1987.

[26] W.W. Bode, Network Analysis and Feedback Amplifier Design, Van Nostrand, Princenton, N.J., 1956.

[27] H. Nyquist. Phys. Rev., 1928, 32, 10.

[28] A. K. Jonscher, Nature, 1977, 267, 673.

[29] A. Garcia-Bernabé, V. Compañ, M. I. Burguete, E. Garcia-Verdugo, N. Karbass, S. V. Luis, E. Riande, J. Phys. Chem. C, 2010, 114, 7030.

[30] N. G. McCrum, B. E. Read, G. Williams, Anelastic and Dielectric Effect in Polymeric Solids, Dover Publications, New York, 1991.

[31] K. W. Wagner, Arch. Electrotechnol. 1914, 2, 371.

[32] K. W. Wagner, Arch. Electrotechnol. 1914, 3, 67.

[33] R. W. Sillars, Proc. Inst. Electr. Eng. Lond., 1937, 80, 378.

[34] R. H. Wiley, B. Davis, J. Polym. Sci., 1960, 46, 423.

[35] C. T. Moynihan, J. Non-Cryst. Sol., 1994, 172-174, 1395; ibid 1996, 203, 359.

[36] C. T. Moynihan, Solid State Ionics, 1998, 105, 175.

[37] S. R. Elliot, J. Non-Cryst. Sol., 1994, 170, 97.

[38] B. Roling, Solid State Ionics, 1998, 105, 185.

[39] I. M. Hodege, K. L. Ngai, C. T. Moynihan, J. Non-Cryst. Solids, 2005, 351, 104.

[40] K. L. Ngai, C. León, Solid State Ionics, 1999, 125, 81.

[41] J. S. Kim, J. Phys. Soc. Jpn., 2001, 70, 3129.

[42] J. Liu, C.-G. Duan, W.-G. Yin, W. N. Mei, R. W. Smith, J. R. Hardy, J. Chem. Phys., 2003, 119, 2812.

[43] S. Havriliak, S. Negami, Polymer, 1967, 8, 161.

[44] E. Neagu, P. Pissis, L;Apekis, J. L. Gomez-Ribelles, J. Phys. D: Appl. Phys., 1997, 30, 1551.

[45] K. L. Ngai, J. Habasaki, Y. Hiwatari, C. Leon. J. Phys.: Condens. Matter., 2003, 15, S1607. 
[46] R. Diaz-Calleja, Macromolecules, 2000, 33, 8924.

[47] Y. Fu, K., Pathmanathan, J. R. Stevens, J. Chem. Phys., 1991, 94, 6323.

[48] G. Williams, D.C. Watts, Trans. Faraday Soc., 1970, 66, 80.

[49] R. Kohlrausch. Prog. Ann. Phys., 1847, 12, 393.

[50] R. Casalini, P. G. Santangelo, C. M., Roland. J. Phys. Chem. B, 2002, 106, 11492.

[51] F. Alvarez, A. Alegría, J. Colmenero,. Physical Review B, 1991, 44, 7306.

[52] H. Vogel, Phys. Z., 1921, 22, 645; b) V. G. Tammann, W. Hesse, Z. Anorg. Allg. Chem., 1926, 156, 245; c) G. S. Fulcher, J. Am. Ceram. Soc., 1925, 8, 339. 


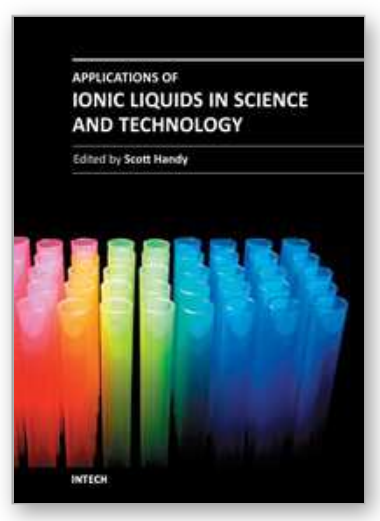

\author{
Applications of lonic Liquids in Science and Technology \\ Edited by Prof. Scott Handy
}

ISBN 978-953-307-605-8

Hard cover, 516 pages

Publisher InTech

Published online 22, September, 2011

Published in print edition September, 2011

This volume, of a two volume set on ionic liquids, focuses on the applications of ionic liquids in a growing range of areas. Throughout the 1990s, it seemed that most of the attention in the area of ionic liquids applications was directed toward their use as solvents for organic and transition-metal-catalyzed reactions. Certainly, this interest continues on to the present date, but the most innovative uses of ionic liquids span a much more diverse field than just synthesis. Some of the main topics of coverage include the application of RTILs in various electronic applications (batteries, capacitors, and light-emitting materials), polymers (synthesis and functionalization), nanomaterials (synthesis and stabilization), and separations. More unusual applications can be noted in the fields of biomass utilization, spectroscopy, optics, lubricants, fuels, and refrigerants. It is hoped that the diversity of this volume will serve as an inspiration for even further advances in the use of RTILs.

\title{
How to reference
}

In order to correctly reference this scholarly work, feel free to copy and paste the following:

Santiago V. Luis, Eduardo Garcîa-Verdugo, M. Isabel Burguete, Andreu Andrio, Sergio Mollá and Vicente Compan (2011). Polymers with lonic Liquid Fragments as Potential Conducting Materials for Advanced Applications, Applications of lonic Liquids in Science and Technology, Prof. Scott Handy (Ed.), ISBN: 978-953307-605-8, InTech, Available from: http://www.intechopen.com/books/applications-of-ionic-liquids-in-scienceand-technology/polymers-with-ionic-liquid-fragments-as-potential-conducting-materials-for-advancedapplications

\section{INTECH}

open science | open minds

\section{InTech Europe}

University Campus STeP Ri

Slavka Krautzeka 83/A

51000 Rijeka, Croatia

Phone: +385 (51) 770447

Fax: +385 (51) 686166

www.intechopen.com

\section{InTech China}

Unit 405, Office Block, Hotel Equatorial Shanghai

No.65, Yan An Road (West), Shanghai, 200040, China

中国上海市延安西路65号上海国际贵都大饭店办公楼 405 单元

Phone: +86-21-62489820

Fax: $+86-21-62489821$ 
(C) 2011 The Author(s). Licensee IntechOpen. This chapter is distributed under the terms of the Creative Commons Attribution-NonCommercialShareAlike-3.0 License, which permits use, distribution and reproduction for non-commercial purposes, provided the original is properly cited and derivative works building on this content are distributed under the same license. 